\title{
Computational Implementation of a Thermodynamically Based Work Potential Model for Progressive Microdamage and Transverse Cracking in Fiber-reinforced Laminates
}

\author{
Evan J. Pineda* and Anthony M. Waas ${ }^{\dagger}$ \\ Brett A. Bednarcyk ${ }^{\ddagger}$ \\ University of Michigan, Ann Arbor, MI 48109 \\ NASA Glenn Research Center, Cleveland, $\mathrm{OH} 44135$ \\ Craig S. Collier $\S$ \\ Collier Research Corporation, Newport News, VA 23607
}

\begin{abstract}
A continuum-level, dual internal state variable, thermodynamically based, work potential model, Schapery Theory, is used capture the effects of two matrix damage mechanisms in a fiber-reinforced laminated composite: microdamage and transverse cracking. Matrix microdamage accrues primarily in the form of shear microcracks between the fibers of the composite. Whereas, larger transverse matrix cracks typically span the thickness of a lamina and run parallel to the fibers. Schapery Theory uses the energy potential required to advance structural changes, associated with the damage mechanisms, to govern damage growth through a set of internal state variables. These state variables are used to quantify the stiffness degradation resulting from damage growth. The transverse and shear stiffness' of the lamina are related to the internal state variables through a set of measurable damage functions. Additionally, the damage variables for a given strain state can be calculated from a set of evolution equations. These evolution equations and damage functions are implemented into the finite element method and used to govern the constitutive response of the material points in the model. Additionally, an axial failure criterion is included in the model. The response of a center-notched, buffer strip-stiffened panel subjected to uniaxial tension is investigated and results are compared to experiment.
\end{abstract}

\section{Introduction}

$\mathrm{D}$ AMAGE and failure analysis of composite materials continues to be prevalent and challenging research topic. The intricacies of damage and failure in composite materials are attributed to numerous sources. The properties of constituent materials, the architecture of the reinforcement material, the interfacial behavior, and the applied loading configuration all influence the type and evolution of damage mechanisms in composite materials. Furthermore, many globally observed damage mechanisms are a result of the interaction of the damage mechanisms in the different phases and across various length scales. It is the interaction of damage mechanisms, due to the heterogeneity of the material, that results in composites behaving more like a structure and is what separates them from monolithic materials. In order to capture the non-linear behavior of composites correctly, the fundamental mechanisms must be modeled using the underlying physics behind those mechanisms. Approaching composite modeling in this manner can lead to very accurate, predictive models; which in turn, can lead to great weight and cost savings in design of composite structures.

For unidirectional, fiber-reinforced, epoxy laminates, numerous damage mechanisms are observed. ${ }^{1}$ Damage first begins in the matrix of the composite at a scale on the order of the fibers. At low stress levels, matrix microdamage arises in the form of micro-void growth, shear microcracks and shear bands between fibers. ${ }^{2,3}$ This damage mechanism is highly distributed and is the primary cause for the globally observed non-linear behavior up to the onset of more severe damage mechanisms. As the load increases transverse cracks begin to nucleate. These cracks typically run parallel to the fibers and span the thickness of a lamina in the fiber-reinforced laminate (FRL). ${ }^{4-10}$ This mechanism occurs on a larger length scale than microdamage. Additionally, the effects of this mechanisms on the overall stiffness

*Ph.D Candidate, Mechanical Engineering Department.

${ }^{\dagger}$ Professor, Aerospace and Mechanical Engineering Departments.

${ }^{\ddagger}$ Materials Research Engineer, AIAA Senior Member.

$\S$ President, Hypersizer Software, AIAA Senior Member 
of the composite are more pronounced. In angle-ply and unidirectional coupons, the initiation of transverse cracking quickly leads to catastrophic failure of the specimen. Although these damage mechanisms are exclusive to the matrix of the FRL, they are heavily influenced by the fiber properties and architectures. Placement of the fibers creates local stress concentrations that nucleate and drive cracks within the materials. Also, the stiff fibers are responsible for arresting matrix crack growth. Thus, the behavior of neat resin is different than the in-situ matrix

Axial (fiber-direction) damage of a ply in a laminate is attributed to damage in the fibers; however, the matrix and fiber/matrix interface also play a role in axial damage. Carbon fibers, used in common FRL applications, usually behave linearly until the fibers rupture suddenly. However in tension, axial failure of composite plies within a laminate is often a combination of fiber breakage and the fiber being pulled out of the surrounding matrix. ${ }^{10-12}$ Fiber-pullout can occur as a macroscopic cracks progress within a laminate. It can result when there is a through-thickness matrix crack, but only some, or none, of the fibers in that region have broken. Fiber-pullout can also arise when fiber failure develops away from the primary fracture plane. In these scenarios the fibers must debond and "pull out" of the surrounding matrix in order for the crack to open further. Thus, fiber-pullout is heavily dependent on the matrix properties and interfacial properties. The onset of axial damage typically indicates that catastrophic failure of the laminate is forthcoming; however the process can be slowed due to fiber-bridging between the two crack faces.

In compression, the globally observed axial damage mechanism is fiber micro-buckling. ${ }^{13-17}$ Small misalignments of the fibers lead to fiber rotation as the structure is loaded. These rotations induce matrix softening in shear; which in turn, leads to further fiber rotations. Eventually, this leads to a runaway instability and a fiber kink band forms.

Often in-plane lamina damage is accompanied by delamination between the layers. Interlamina damage occurs when adjacent layers displace relative to each other and the bond between those layers is weakened. Delamination can result from edge effects, or it may develop when a matrix crack, within a ply, reaches the interface of the adjacent lamina. It has been shown experimentally that delamination can influence the globally observed failure modes of open-hole tension, composite specimens. ${ }^{18-20}$ At the same time, in compression of open hole specimens, it has been shown that fiber kink banding is dominant and leads to delamination formation. ${ }^{21-23}$

There exist numerous approaches to modeling damage mechanisms in a composite. Some methods for capturing in-plane damage mechanisms at the continuum-level include using empirical failure criteria, continuum damage mechanics, and/or fracture mechanics and discontinuous methods. ${ }^{10,12,24-33}$ In-plane damage mechanisms can also be captured with micromechanics models including repeating unit cell (RUC) and representative volume element (RVE) techniques, as well as other methods. ${ }^{54-39}$ Moreover, micromechanics models can be tied to the continuum scale using multiscale methods in which the RUC is homogenized to give the effective response of the continuum. ${ }^{40-45}$ Commonly used techniques for introducing interlamina damage into a composite simulation include the virtual crack closure technique (VCCT), cohesive zone model (CZM) ${ }^{10,46-48}$ and discrete cohesive zone model (DCZM) ${ }^{49-52}$ Additionally multiscale methods can also be used to simulate interlamina effects. ${ }^{53}$

The method presented in this work uses three different models to encapsulate the effects of various damage mechanisms in an FRL. Matrix microdamage and transverse cracking are modeled using a dual internal state variable (ISV) formulation of the thermodynamically based work potential model developed by Schapery, and presented in ${ }^{24}$ Single and dual ISV formulations of Schapery Theory (ST) have been used to model microdamage alone and both microdamage and transverse cracking in analytical and numerical frameworks. ${ }^{2,17,54,55}$ Lamina-level ST represents each layer as a homogenized continuum and uses the amount of energy necessary to advance structural changes within the material, associated with the damage mechanisms, to govern damage growth in a thermodynamically consistent manner. Each damage mechanism is accounted for through separate ISVs which are related to the degraded stiffness' through a set of measurable damage functions. In this paper, ST is implemented into the finite element method (FEM) and is used to control the constitutive behavior of the elements. Additionally, a simple maximum strain axial failure criterion in used for axial failure. Upon satisfaction of the criterion, the stiffness of the corresponding material point is significantly degraded. A more physically-based model for axial failure is desired and will be included in future models. Finally, delamination is included in the model via cohesive elements. The details of the finite element model, including the ST implementation, and axial failure are presented in Section IV.

Center-notched, IM7/8552 panels were tested in uniaxial tension at the NASA Langley Research Center. ${ }^{56}$ Two, one inch sections, spanning the length of the panels, were reinforced with additional $0^{\circ}$ plies. These sections, referred to as buffer strips, were included to increase the ultimate load of the panels, without introducing too much additional weight, and to change the failure mode of the panels. The experimental program is outlined in Section III. Section IV provides details of an FEM model of the buffer strip panel. The global load versus displacement and local strain gage data from the experiment are compared to the results of the FEM model in Section V. Additionally, analysis of the damage and failure mechanisms observed in the FEM model is provided in Section V. 


\section{Thermodynamically Based Work Potential Model}

A thermodynamically based framework for modeling elastic solids undergoing structural changes was developed by Schapery, 24. In this theory the total work potential $W_{T}$ is partitioned into a recoverable, elastic portion $W$, and a dissipated, or inelastic, part $W_{S}$.

$$
W_{T}=W+W_{S}
$$

As the material is loaded, a portion of the applied work potential facilitates structural changes in the material. The evolution of these structural changes affects the elastic properties of the material. However, a fraction of the total applied work potential is recovered when the material is unloaded. The magnitude of energy recovered is contingent upon the current, degraded elastic properties. It is assumed upon subsequent reloading, the material behaves linearly, exhibiting the elastic properties observed during unloading, until it reaches the previous maximum strain state. After this state is achieved, structural changes resume further degrading the elastic moduli of the material. This secant assumption is not mandatory and may be relaxed depending on the material, but it is acceptable for fiber reinforced composites exhibiting low levels of plastic deformation and viscoelastic behavior. ${ }^{2}$ This process is displayed in Figure 1 in the form of a typical stress-strain curve for a material under uniaxial tension. The shaded area under the linear unloading curve is the recoverable, elastic strain energy density $W$ and the remaining area under the curve is the dissipated energy per unit initial volume $W_{S}$.

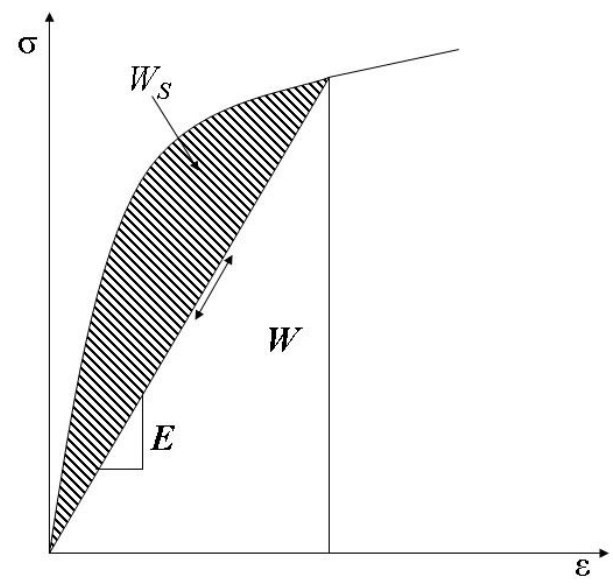

Figure 1. Typical stress-strain curve displaying the elastic $(W)$ and irrecoverable $\left(W_{S}\right)$ potentials.

Both $W$ and $W_{S}$ are functions of a set of internal state variables (ISVs), $S_{m},(m=1,2, M)$. These ISVs account for any inelastic structural changes in the material. Differentiating $W_{S}$ with respect to any ISV, $S_{m}$ yields the thermodynamic driving force, $f_{m}$, available for producing structural changes associated with the $m^{t h}$ ISV.

$$
f_{m}=\frac{\partial W_{s}}{\partial S_{m}}
$$

It is shown in Ref. 24 that the total work potential is stationary with respect to each ISV.

$$
\frac{\partial W_{T}}{\partial S_{m}}=0
$$

Additionally, Rice $^{57}$ has shown that according to the second law of thermodynamics:

$$
f_{m} \dot{S}_{m} \geq 0
$$

Equations (2), (3), and (4) form the foundation of a thermodynamically based work potential model for nonlinear structural changes in a material. If one of the ISVs is chosen to be crack length, Equation 3 is analgous to Griffith's criterion commonly used in fracture mechanics. ${ }^{58}$

\section{II.A. Dual-ISV formulation of ST to model progressive microdamage and transverse cracking}

The generality of the evolution equations, presented in the previous section, allows for the response of a material undergoing any number and type of structural changes to be captured. This is especially useful for modeling progressive 
damage in composites because multiple damage mechanisms arise during a typical loading history due to the heterogeneity of the material. For instance in the matrix phase alone, microdamage accrues until its effects are superseded by the growth of larger transverse cracks. Microdamage is considered the advancement of microcracks, voids, fissures, shear bands, and other flaws that are present in the matrix of a composite. ${ }^{2,3,17,54}$ The size of these flaws is typically on the order of that of the fiber or smaller. Transverse cracks nucleate from preexisting flaws within the matrix but grow parallel to the fibers and span the thickness of the lamina. ${ }^{5,6,8,10,18,59,60}$ Often, the growth of individual transverse cracks is extremely rapid; however, the effects of transverse cracking on the stiffness of a composite laminate can be progressive if multiple cracks form over an extended period of time. Eventually, transverse cracking is succeeded by more catastrophic damage mechanisms like interlamina delamination, fiber breakage, pull-out and bridging associated with laminate fracture. ${ }^{11,47,61}$

The average behavior of numerous coupon level laminates exhibiting progressive microdamage and transverse cracking was successfully modeled in Refs. 2,54 using ST. A similar formulation will be used in this work, in conjunction with the FEM, to model more complicated laminates. To incorporate microdamage and transverse cracking into ST, it is assumed that the inelastic work potential $W_{S}$ is a function of two ISVs: $S$ which accounts for energy dissipation via microdamage and $S_{C}$ which captures available energy to form and advance transverse cracks. It can be assumed that these ISVs are equal to the energy density required for the advancement of the associated mechanism. Although interaction between the mechanisms occurs through coupling in the evolution laws and adjustment of the stress and strain fields with increasing damage, it is assumed that these ISVs are independent; in that, microdamage evolution does not directly influence the growth of transverse cracks and vice versa. Thus, the total amount of dissipated energy is a sum of the available energy used to progress each individual mechanism: $W_{S}=S+S_{c}$. The total energy is then given by

$$
W_{T}=W+S+S_{C}
$$

Applying stationarity of potential energy (Equation (3)) to the definition of the total work potential yields two evolution equations.

$$
\begin{aligned}
& \frac{\partial W}{\partial S}=-1 \\
& \frac{\partial W}{\partial S_{C}}=-1
\end{aligned}
$$

Additionally, invoking Equation (4) results in statements of the inadmissability of healing for both microdamage and transverse cracking.

$$
\begin{array}{r}
\dot{S} \geq 0 \\
\dot{S_{C}} \geq 0
\end{array}
$$

Equations (8) and (9) dictate that the amount of energy used to progress microdamage and transverse cracking can never decrease; therefore, that energy has been dissipated into creating structural changes and cannot be recovered. The combination of Equations (6)-(9) represent the evolution equations for microdamage and transverse cracking in the matrix of the composite.

\section{II.B. Application of dual-ISV ST to fiber reinforced laminae}

\section{II.B.1. 2-D plane stress constitutive law}

To tailor the evolution equations presented in Section II.A to a unidirectional, fiber reinforced lamina, the stress-strain relationships can be defined, under plane stress assumptions, in the principal material coordinates of the lamina as

$$
\begin{aligned}
& \sigma_{11}=Q_{11} \epsilon_{11}+Q_{12} \epsilon_{22} \\
& \sigma_{22}=Q_{12} \epsilon_{11}+Q_{22} \epsilon_{22} \\
& \tau_{12}=Q_{66} \gamma_{12}
\end{aligned}
$$

where $\sigma_{i j}$ are the stress components, $\epsilon_{i j}$ are the strain components, the 1-direction is aligned with the fibers in the lamina, the '2-direction is perpendicular to the fibers, $\gamma_{12}$ is the engineering shear strain and $Q_{i j}$ are the components 
of the stiffness matrix given by

$$
\begin{aligned}
Q_{11} & =\frac{E_{11}}{1-\nu_{12} \nu_{21}} \\
Q_{22} & =\frac{E_{22}}{1-\nu_{12} \nu_{21}} \\
Q_{12} & =\nu_{12} Q_{22} \\
Q_{66} & =G_{12} \\
\nu_{21} & =\frac{\nu_{12} E_{22}}{E_{11}}
\end{aligned}
$$

where $E_{11}$ is the axial elastic modulus, $E_{22}$ is the transverse elastic modulus, $\nu_{12}$ is the Poisson's Ratio, $\nu_{21}$ is the transverse Poisson's Ratio and $G_{12}$ is the elastic shear modulus. ${ }^{62}$ After assuming that the quantity $\nu_{12} \nu_{21}<<1$, Equations (11) become,

$$
\begin{aligned}
Q_{11} & =E_{11} \\
Q_{22} & =E_{22} \\
Q_{12} & =\nu_{12} Q_{22} \\
Q_{66} & =G_{12}
\end{aligned}
$$

\section{II.B.2. Determining the damage state}

It is necessary to define the manner in which the moduli degrade as functions of the ISVs. Since the damage mechanisms associated with $S$ and $S_{C}$ accrue only in the matrix of the composite, it is assumed that the moduli affected by this damage are limited to $E_{22}$ and $G_{12}$. These moduli can be written as functions of $S$ and $S_{C}$.

$$
\begin{aligned}
& E_{22}=E_{220} e_{s}(S) e_{c}\left(S_{C}\right) \\
& G_{12}=G_{120} g_{s}(S) g_{c}\left(S_{C}\right)
\end{aligned}
$$

where $E_{220}$ and $G_{120}$ are the undamaged transverse and shear elastic moduli, $e_{s}(S)$ and $g_{s}(S)$ are factors relating the transverse and shear moduli to the microdamage $S, e_{c}\left(S_{C}\right)$ and $g_{c}\left(S_{C}\right)$ are functions relating the moduli to the transverse cracking ISV $S_{C}$. Sicking provided a procedure for determining the damage functions experimentally. ${ }^{2}$ The experimental damage curves can then be fit with polynomials (such that values at $S=0$ and $S_{C}=0$, are $E_{22}=E_{220}$ and $G_{12}=G_{120}$ ) and used in Equations (13) and (14).

The elastic strain energy density $W$

$$
W=\int \sigma_{i j} d \epsilon_{i j}
$$

can be written using the plane stress constitutive relationships.

$$
W=\frac{1}{2}\left(E_{11} \epsilon_{11}^{2}+E_{22} \epsilon_{22}^{2}+G_{12} \gamma_{12}^{2}\right)+Q_{12} \epsilon_{11} \epsilon_{22}
$$

Employing Equations (6) and (7) with (13), (14), and (16), while assuming the quantity $Q_{12}=\nu_{12} Q_{22}$ is constant (independent of $S$ and $S_{C}$ ), yields two ordinary differential equations which are be solved simultaneously for $S$ and $S_{C}$.

$$
\begin{aligned}
& \frac{\epsilon_{22}^{2}}{2} \frac{\partial E_{22}}{\partial S}+\frac{\gamma_{12}^{2}}{2} \frac{\partial G_{12}}{\partial S}=-1 \\
& \frac{\epsilon_{22}^{2}}{2} \frac{\partial E_{22}}{\partial S_{C}}+\frac{\gamma_{12}^{2}}{2} \frac{\partial G_{12}}{\partial S_{C}}=-1
\end{aligned}
$$

The above equations indicate that the microdamage and transverse cracking states depend only on the strain state, elastic properties, and damage functions. Furthermore, Equations (17) and (18) preclude the use of any failure criteria to determine the onset of matrix damage or failure. Since the damage functions are measured quantities, the evolution equations are representative of the actual material response. The damage functions and slopes of the damage functions dictate how quickly the ISVs evolve. Thus for low strain levels, the damage ISVs remain small and have a negligible effect on the response of the material. At intermediate strain levels the influence of the microdamage ISV becomes more prevalent. At larger strain levels, the transverse cracking ISV begins to increase more rapidly. At even higher strain levels, the ISVs are so large that the transverse and shear stiffness begin to approach zero. 
Experimentally it has been determined that $S$ and $S_{C}$ behave as $\epsilon^{3}$, thus it is convenient to introduce reduced damage variables $S_{r}$ and $S_{c r}{ }^{2}$

$$
\begin{aligned}
S_{r} & \equiv S^{1 / 3} \\
S_{c r} & \equiv S_{C}^{1 / 3}
\end{aligned}
$$

Furthermore, the use of reduced ISVs yields polynomial damage functions. With the reduced ISVs, the evolution equations, Equations (17) and (18), become

$$
\begin{aligned}
& \frac{\epsilon_{22}^{2}}{2} E_{220} \frac{d e_{s}\left(S_{r}\right)}{d S_{r}} e_{c}\left(S_{c r}\right)+\frac{\gamma_{12}^{2}}{2} G_{120} \frac{d g_{s}\left(S_{r}\right)}{d S_{r}} g_{c}\left(S_{c r}\right)=-3 S_{r}^{2} \\
& \frac{\epsilon_{22}^{2}}{2} E_{220} e_{s}\left(S_{r}\right) \frac{d e_{c}\left(S_{c r}\right)}{d S_{c r}}+\frac{\gamma_{12}^{2}}{2} G_{120} g_{s}\left(S_{r}\right) \frac{d g_{c}\left(S_{c r}\right)}{d S_{c r}}=-3 S_{c r}^{2}
\end{aligned}
$$

Once $S_{r}$ and $S_{c r}$ are determined from Equations (21) and (22), while ensuring Equations (8) and (9), the transverse and shear moduli can be degraded accordingly using Equations (13) and (14).

It is important to note that ST can account for compressive failure of a laminate resulting from fiber microbuckling and kink band formation within the laminae. As a material point is loaded, the fibers begin to rotate. All calculations are performed in the instantaneous material frame by tracking the fiber angle and transforming the field variables accordingly. These rotations induce large, localized shear strains which, in turn degrade the matrix shear modulus, allowing the fibers to rotate more easily. If the loading is compressive, this feedback will lead to a runaway instability and regions of microbuckled, or kinked, fibers will develop. In previous studies, ${ }^{17}$ where the loading was compression dominated, the instantaneous fiber rotation is captured in conjunction with ST. This has the advantage of predicting fiber kinking failure, from a knowledge of basic constituent level properties, avoiding the use of an explicit fiber direction compressive strength criterion, and the need for an additional coupon level test to measure compression strength, $X_{c}$.

\section{II.B.3. Decoupling the evolution equations}

To obtain a solution for Equations (21) and (22) the damage functions must be explicitly defined. Typically fourth order, or higher order, polynomials are used for the microdamage and transverse cracking damage functions. The use of these polynomial damage functions results in two coupled, bivariate polynomial evolution equations. The solution of these equations produces numerous values for $S_{r}$ and $S_{c r}$. Only one set of solutions represents the physical behavior of the material, the remaining solutions are mathematical artifacts. However to determine the correct solutions, all solutions to the evolution equations must be obtained. This solution procedure can quickly become cumbersome and computationally time consuming.

The solution of the evolution equations can be greatly simplified if the effects of microdamage and transverse cracking on the transverse and shear stiffness are decoupled. Microdamage primarily manifests as shear microcracks between fibers. ${ }^{3}$ A photograph of a $[+45 /-45]_{S}$ composite specimen displaying these shear microcracks, taken under a scanning electron microscope (SEM), is presented in Figure 2. Additionally, the influence of transverse cracking on the shear modulus of a composite laminate is minimal. ${ }^{2}$ Thus, the evolution equations can be decoupled by assuming that the shear modulus is affected only by microdamage, and the transverse stiffness is affected only by transverse cracking.

$$
\begin{aligned}
& E_{22}=E_{220} e_{c}\left(S_{c r}\right) \\
& G_{12}=G_{120} g_{s}\left(S_{r}\right)
\end{aligned}
$$

Using these relationships, the decoupled evolution equations are

$$
\begin{aligned}
\frac{\gamma_{12}^{2}}{2} G_{120} \frac{d g_{s}\left(S_{r}\right)}{\left.d S_{r}\right)} & =-3 S_{r}^{2} \\
\frac{\epsilon_{22}^{2}}{2} E_{220} \frac{d e_{c}\left(S_{c r}\right)}{d S_{c r}} & =-3 S_{c r}^{2}
\end{aligned}
$$

Even though the interaction between microdamage and transverse cracking is lost by decoupling the evolution equations, the solution procedure is greatly simplified making it more amenable for implementation into a finite element model where the evolution equations will need to be solved for every applicable material point at every time increment. As stated earlier, there is evidence to suggest that the uncoupled equations for damage evolution in laminated composites is valid,. ${ }^{2}$ 


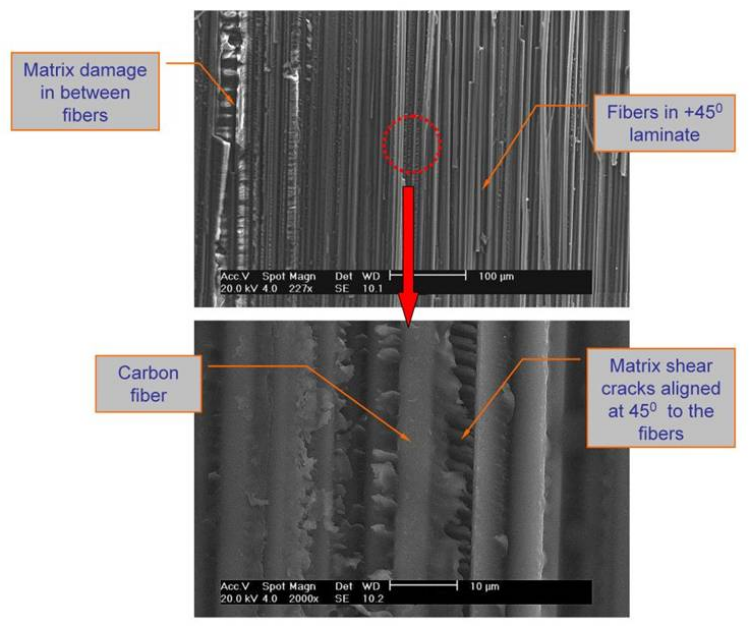

Figure 2. SEM photograph showing shear microcracks in damaged $[+45 /-45]_{S}$ specimen.

\section{Experimental Program at NASA Langley}

The response of IM7/8552 center-notched panels reinforced with buffer strip stiffeners was investigated at the NASA Langley Research Center (LaRC) under the supersonics program, ${ }^{56}$ The panels (Figure 3) consist of a flat 12" x 34" composite laminate. The laminate was reinforced with two 1" wide buffer strips located 1.5" from each edge. These buffer strips contained eight additional $0^{\circ}$ plies not present in the rest of the laminate. Figure 4 displays the cross section of the stiffened regions. The stacking sequences and thicknesses for the base laminate and buffer strip regions are given in Table 1. The flat plate and buffer strips were co-cured as a single part. After the pristine panel was cured, a centered notch that was 3" long and had notch tip diameter of 0.09735 " was machined in the panel. 5" x 12" steel grips were adhered to the ends panel. The grips where manufactured so they would conform to the faces of the panel. One component of each set of grips was machined to accommodate the buffer strips, and the other component was left flat. The bottom grip was clamped, preventing any displacements or rotations. The top grip was secured to prevent any rotations or displacements in the $x$ - or $z$-directions, while a tensile displacement of $5 \mathrm{E}-5 \mathrm{in} . / \mathrm{sec}$. was applied in the $y$-direction until the specimen failed catastrophically. Several strain gages, shown in Figure 3, were affixed to the specimen and were monitored during loading of the specimen along with the applied load and edge displacement.

\begin{tabular}{|c|c|c|}
\hline Region & Stacking & Thickness (in.) \\
\hline \hline Flat Panel & {$\left[45^{\circ} / 90^{\circ} /-45^{\circ} / 0^{\circ}\right]_{S}$} & 0.044 \\
\hline Buffer Strip & {$\left[45^{\circ} / 90^{\circ} /-45^{\circ} / 0_{5}^{\circ}\right]_{S}$} & 0.088 \\
\hline
\end{tabular}

Table 1. Panel stacking sequence and thickness in flat and buffer strip-reinforced regions.

The buffer strips were added to the base laminate to increase the ultimate strength of the center-notched panels without a substantial weight increase. Moreover, the intention of the buffer strips was to alter the failure mode of the panel. Additional buffer strip configurations, not presented here, were also tested. These panels exhibited self similar crack growth propagating from the notch tip towards the free edge. Upon reaching the buffer strips, however, the direction of damage propagation turns so that the damage runs parallel to the buffer strip towards the gripped edge. This behavior was not observed with the buffer strip configuration presented in this paper. Instead, the crack like damage was arrested briefly at the buffer strip boundary before proceeding through the buffer strip towards the free edge. Three specimens with the lay-up presented in Table 1 were tested in all. There was scatter in the ultimate loads of these three samples.

The elastic properties for IM7/8552 are taken from Ref. ${ }^{32}$ and given in Table 2. The shear microdamage curve was obtained from a $[+45 /-45]_{5}$ tensile dogbone specimens. The normal transverse cracking damage curve was obtained from multi-angle AS4/3502 specimens. ${ }^{2}$ The coefficients of this curve were scaled by the ratio of the elastic $E_{220}$ for IM7/8552 to the elastic $E_{220}$ for AS4/8502.

$$
e_{c i}^{\mathrm{IM} 7 / 8552}=\frac{E_{220}^{\mathrm{IM} 7 / 8552}}{E_{220}^{\mathrm{AS} 4 / 3502}} e_{c i}^{\mathrm{AS} 4 / 3502}, \quad i \neq 0
$$




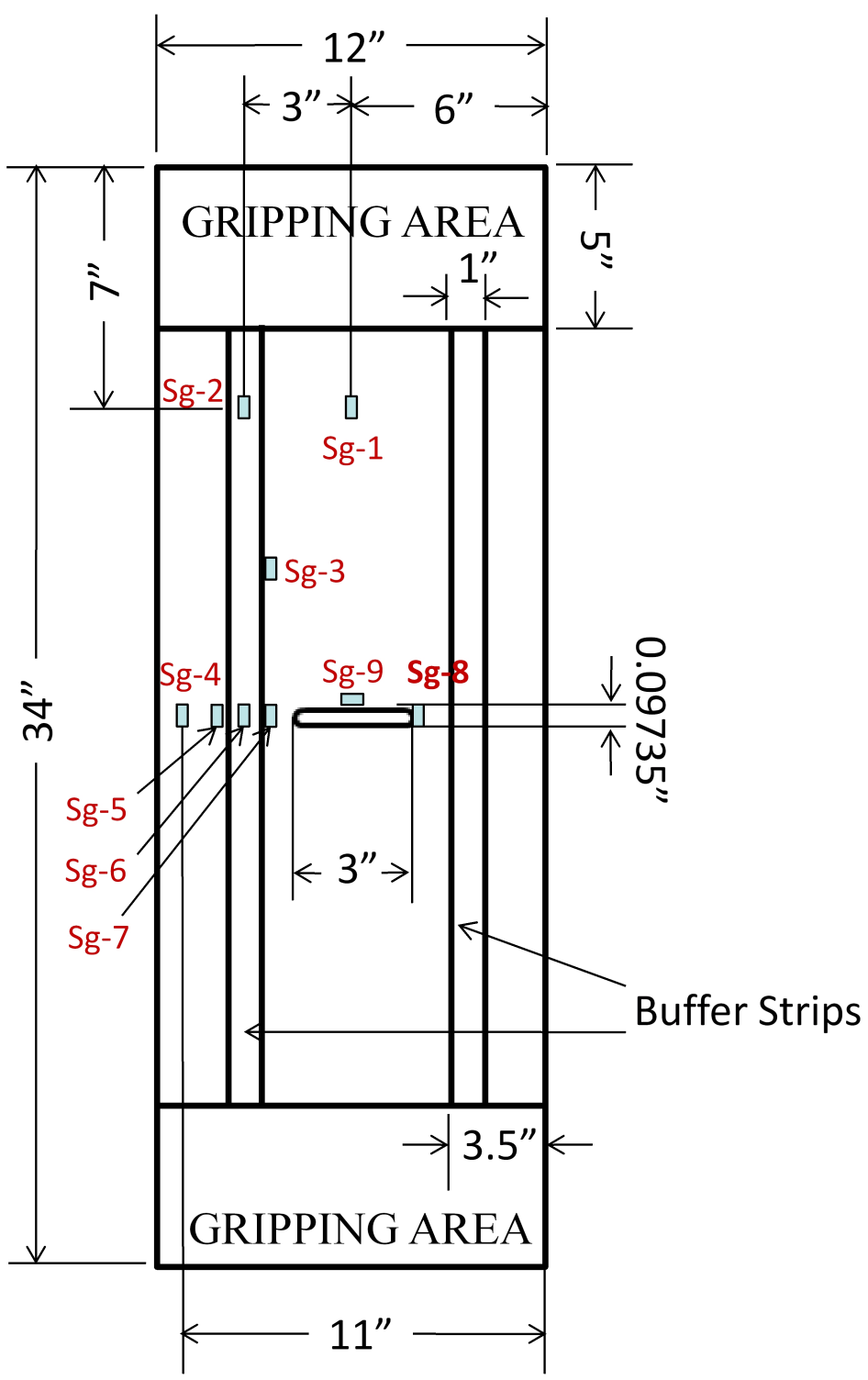

Figure 3. Schematic of center-notched, buffer strip reinforced, tensile specimen.

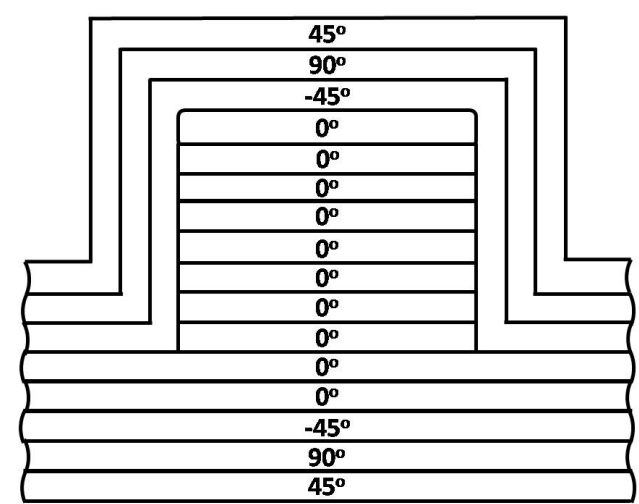

Figure 4. Schematic of cross-section of buffer strip reinforced regions. 
This scaling procedure was used in the successful failure prediciton of notched compression specimens as reported in, ${ }^{63}$ Figures 5 and 6 show the shear microdamage curve and normal transverse cracking damage curve as functions of the respective reduced ISVs. The coefficients of the polynomial curves are presented in Table 3.

\begin{tabular}{|l|r|}
\hline Property & Value \\
\hline \hline$E_{11}(\mathrm{msi})$ & 24.86 \\
\hline$E_{22}(\mathrm{msi})$ & 1.78 \\
\hline$\nu_{12}$ & 0.32 \\
\hline$G_{12}(\mathrm{msi})$ & 0.68 \\
\hline
\end{tabular}

Table 2. Elastic properties and axial strain allowable for IM7/8552.

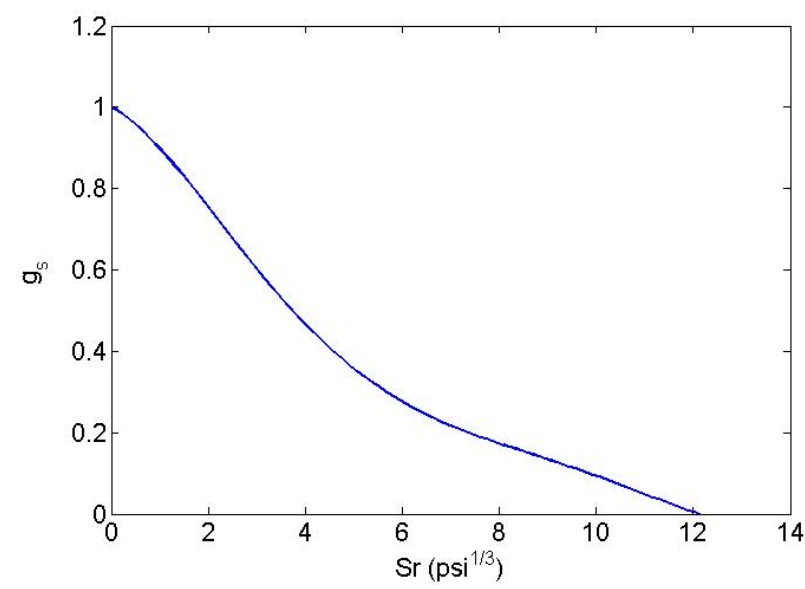

Figure 5. Shear microdamage function.

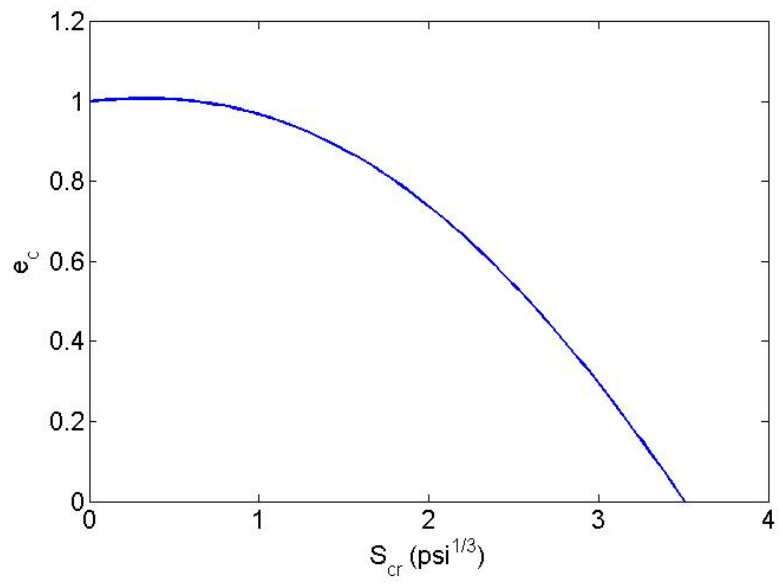

Figure 6. Normal transverse cracking damage function.

\section{Finite Element Model}

\section{IV.A. Finite element discretization and boundary conditions}

One quarter of the center-notched, buffer-strip panel, presented in Section III, was discretized using ABAQUS, S4R, 4-noded, quadrilateral and S3R, 3-noded, triangular, two-dimensional (2D), plane stress, shell elements. ${ }^{64}$ This mesh contained 9257 S4R and 42 S3R elements, with a high density of elements near the notch tips to the free edge of the 


\begin{tabular}{|l|l|l|l|l|l|l|}
\hline Function & $c_{0}$ & $c_{1}$ & $c_{2}$ & $c_{3}$ & $c_{4}$ & $c_{5}$ \\
\hline \hline$g_{s}\left(S_{r}\right)$ & 1.0000 & $-6.3955 \mathrm{E}-2$ & $-4.7716 \mathrm{E}-2$ & $1.0566 \mathrm{E}-2$ & $-8.3609 \mathrm{E}-4$ & $2.2997 \mathrm{E}-5$ \\
\hline$e_{c}\left(S_{c r}\right)$ & 1.0000 & $4.9809 \mathrm{E}-2$ & $-6.7644 \mathrm{E}-2$ & $-1.5854 \mathrm{E}-2$ & $2.2461 \mathrm{E}-3$ & 0.0000 \\
\hline
\end{tabular}

Table 3. Polynomial coefficients of damage curves.

panel. The high density regions were chosen to accurately capture the fields near the notch tip and along the expected axial failure path. This mesh is displayed in Figure 7. The portions highlighted in green indicate buffer strip-reinforced regions.

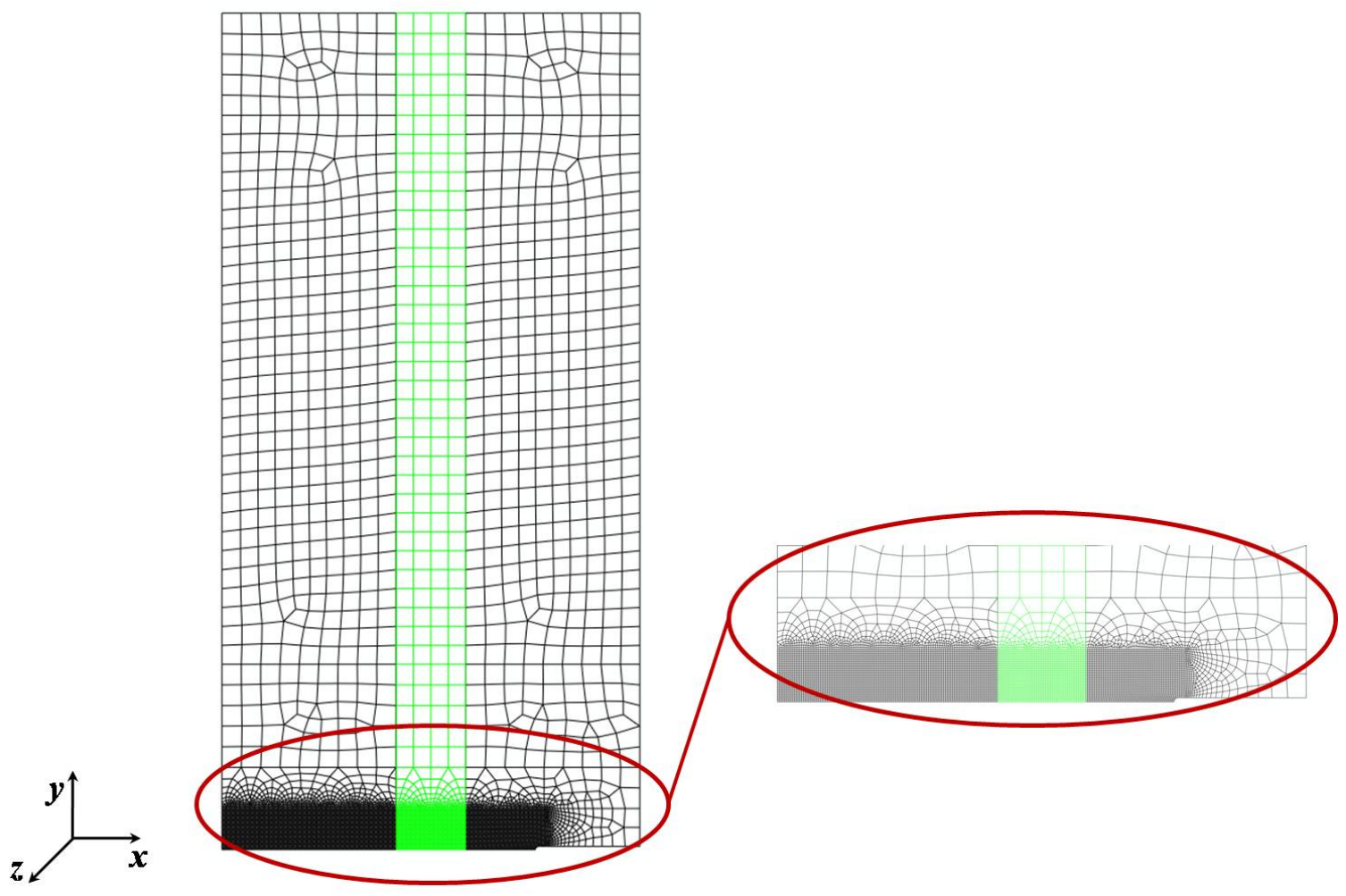

Figure 7. Finite element mesh of quarter of buffer strip panel domain. Buffer strip reinforced elements highlighted in red.

Displacements in the $x-, y$-, and $z$-directions as well as all rotations along the bottom edge of all the panel are constrained. Similarly for the top edges, the displacements in the $x$ - and $z$-directions and all rotations are prohibited. A uniform displacement in the $y$-direction is applied dynamically at a rate of $0.886 \mathrm{in}$./sec. up to $0.0886 \mathrm{in}$. over a duration of $0.1 \mathrm{sec}$. Initially, mass scaling is introduced into the model on an element by element basis, using the ABAQUS/Explicit command $\star$ MASS SCALING, to increase the minimum stable time increment of the problem to $1.0 \mathrm{E}-5 \mathrm{sec}$. The input deck card $\star$ VARIABLE MASS SCALING is also used to scale the mass of the elements every 1000 time increments if necessary.

\section{IV.B. In-plane damage and failure}

The dual ISV ST is implemented into the FEM model using the commercially available ABAQUS 6.8-1 finite element software. ${ }^{64}$ The ST constitutive laws are integrated into ABAQUS/Standard through a user material subroutine (UMAT). Axial failure is also included in the UMAT to capture the effects of fiber breakage and other axial failure mechanisms. Prior to calculating the damage state of the material point, an axial maximum strain failure criterion is evaluated,

$$
e_{f}=\frac{\epsilon_{11}}{\epsilon_{11}^{U}}
$$

where $\epsilon_{11}$ is the strain in the fiber direction of the layer and $\epsilon_{11}^{U}$ is the ultimate strain. If $e_{f} \geq 0$ the element is deleted and removed from subsequent calculations. If axial failure has not occurred; then, at each integration point in an 
element obeying ST, the local strain fields are used in Equations (25) and (26) to calculate $S_{r}$ and $S_{c r}$. Equations (8) and (9) are enforced manually; if an ISV decreases, the value of the ISV at the end of the previous increment is used. Once the damage state is determined, the transverse and shear stiffness' are updated using Equations (23) and (24). The stress field is then calculated using the degraded moduli and Equation (10).

The IM7/8552 lamina elastic properties are given in Table 2, and the damage function coefficients are presented in Table 3. It should be mentioned that the axial failure criterion, Equation (28) and the degradation scheme used are very mesh dependent. The experimental, average, maximum value of strain near the notch ( $\mathrm{Sg}-8)$ was used to estimate the maximum strain allowable for the simulation. This strain allowable was 2992 microstrain $(\mu \epsilon)$. Due to the very steep strain gradients near the notch, the average strain in a region the size of the element used at the notch tip in the simulation would be far less than the strain reported by the strain gage. Therefore, the experimentally obtained strain allowable was reduced by $25 \%$ to arrive at an average allowable for the axial failure strain of the elements used in the model. The value used was $\epsilon_{11}^{U}=2250 \mu \epsilon$. Ongoing studies will include a sensitivity analysis of $\epsilon_{11}^{U}$ to examine how it influences the overall results of the model. Additionally, future models will incorporate more sophisticated axial failure models that can account for pullout and friction during axial failure of a fiber composite, ${ }^{65}$ as well as possible non-local effects, $;{ }^{66}$ thus, alleviating the dependence of axial failure on mesh size and density.

\section{Results}

\section{V.A. Quantitative results compared to experimental data}

Three center-notched, buffer strip-reinforced panels were tested under uniaxial tension at NASA LaRC. Load versus edge displacement as well as local strain gage data was recorded. The location of the strain gages is displayed in Figure 3. Each strain gage shown in the diagram represents multiple strain gages placed in equivalent locations on the panel. The data presented here is the average value of those analogous strain gage readings.

A comparison of the global load-deflection curve obtained from the model to those from experiment is plotted in Figure 8. The simulation is able to capture both the linear and non-linear load versus displacement response of the panel. There is scatter between experimental results for the nominally same panel. The ultimate loads $\left(P^{u} l t\right)$ for the three panels were 37,407 lb., 30,451 lb., and 23,471 lb. Thus, the average ultimate load for the three tests was $30,443 \mathrm{lb}$. with a standard deviation of $6,968 \mathrm{lb}$. The finite element model yielded an ultimate load of 32,844 which is approximately $8 \%$ greater than the average. This indicates that the $25 \%$ reduction imposed on the average maximum strain near the notch tip to obtain the axial failure strain allowable was slightly non-conservative, or that energy was dissipated via other damage mechanisms not included in the finite element model, such as delamination or fiber bridging. The ultimate loads are summarized in Table 4. In addition to an adequate ultimate load prediction, the simulation also exhibits similar discontinuous load-drops, that are seen in the experimental results, prior to reaching the ultimate load. This may indicate that the failure and damage mechanism evolution predicted with the finite element model are accurate. An overview of these damage and failure mechanisms are presented in the next section.

Figure 9 shows the ratio of the kinetic energy $(K E)$ to the total energy ( $E_{T o t a l}$ of the system as a function of time. The kinetic energy remains less than 5\% of the total energy throughout the simulation except at the very beginning of the model (well within the linear regime), and just prior to ultimate failure. This indicates that the mass scaling and rapid loading rate used to speed up the total simulation time are not influencing the results in a non-physical manner.

Local strain gage data for the nine gages (see Figure 3) are plotted in Figure 10. The linear stiffness of the numerical model is not in correspondence with any of the strain gage stiffness'. It should be noted that there is a discrepancy between the stiffness of the experimental load-displacement curve and the load-axial strain curve of Sg-1 far away from the notch. The reason for this discrepancy has yet to be uncovered; however, the trends predicted by the finite

\begin{tabular}{|c|c|c|}
\hline & Load (lb.) & $\begin{array}{c}\text { Deviation from } \\
\text { Experimental Average }\end{array}$ \\
\hline \hline Test1 & 37,407 & $23 \%$ \\
\hline Test2 & 30,451 & $0.0003 \%$ \\
\hline Test3 & 23,471 & $23 \%$ \\
\hline Average & 30,443 & N/A \\
\hline FEM & 32,884 & $8 \%$ \\
\hline
\end{tabular}

Table 4. Ultimate load information for experiments and finite element model. 


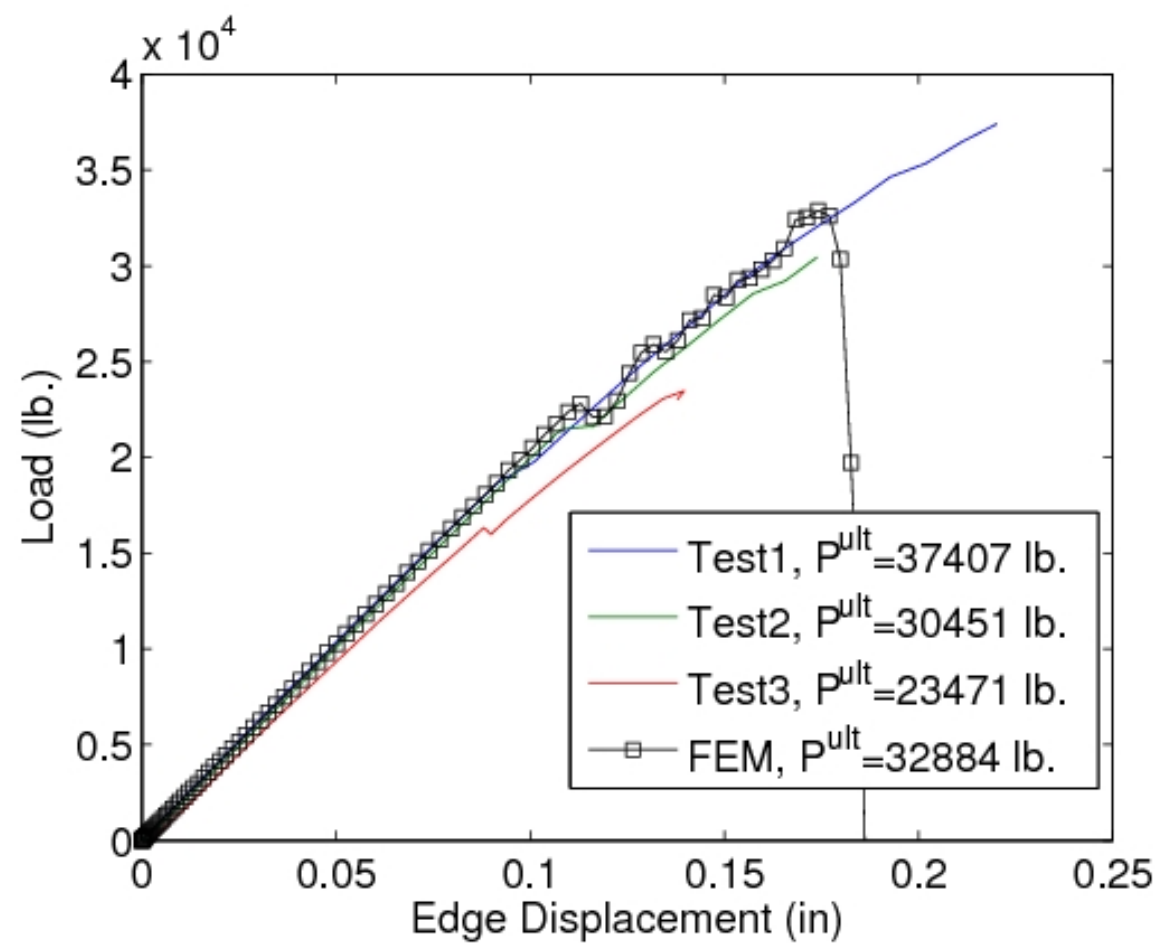

Figure 8. Experimental and numerical load vs. displacement data for buffer strip panel.

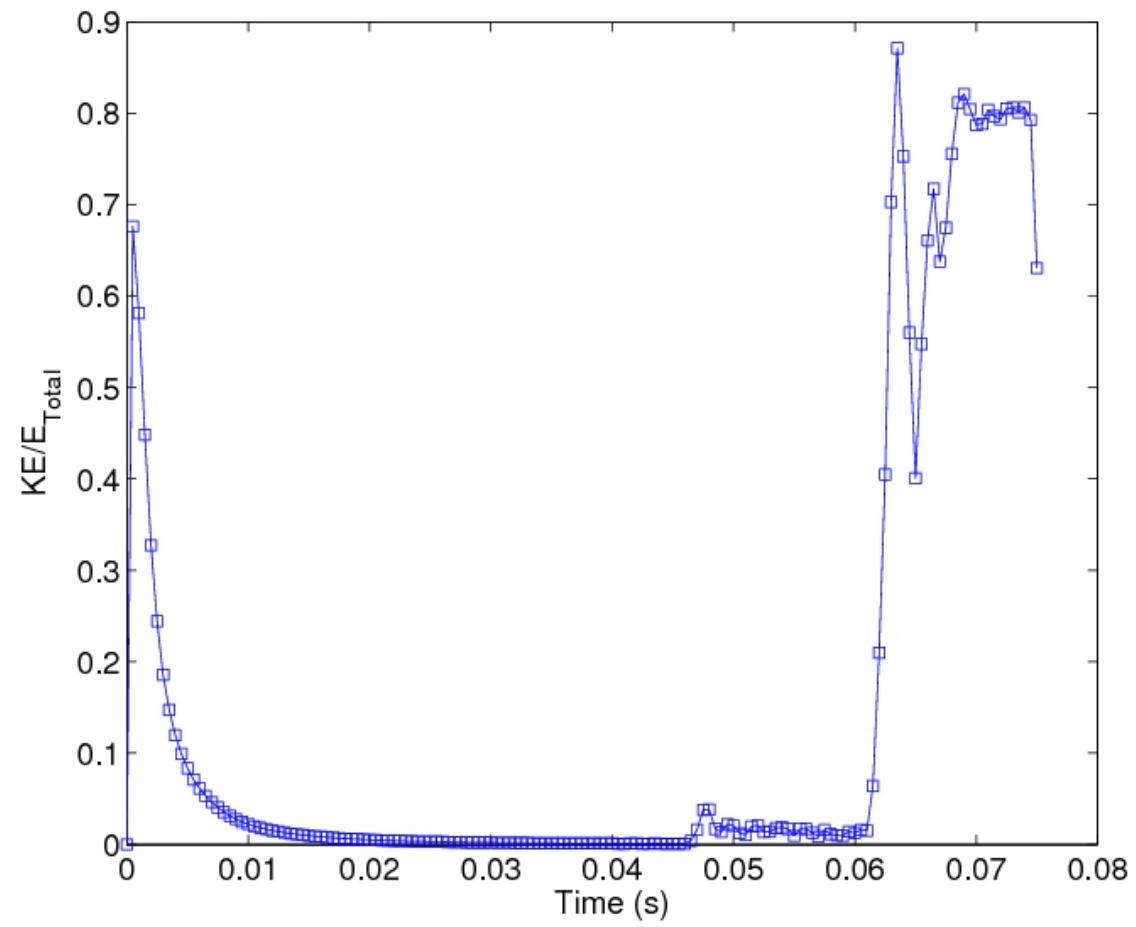

Figure 9. Kinetic energy history. 
element model can still be compared to those observed in the experiment. Since the ultimate load obtained from the model was closest to that in Test2, local model data will be compared most closely to that test.

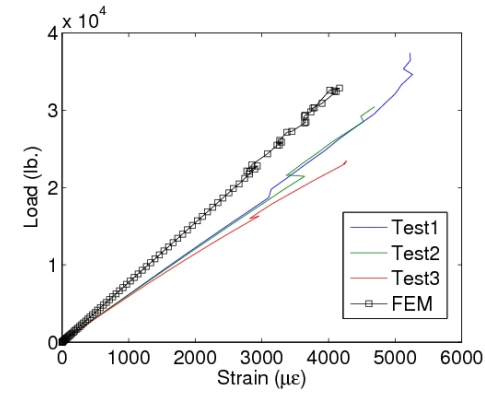

(a) $\mathrm{Sg}-1$

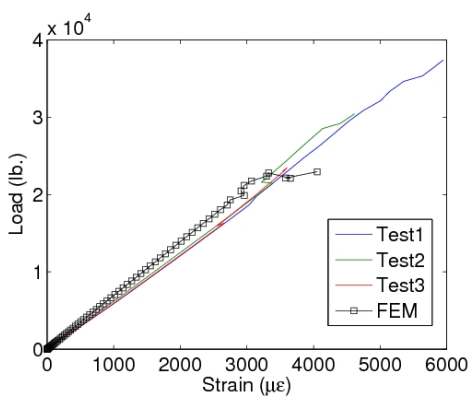

(d) $\mathrm{Sg}-4$

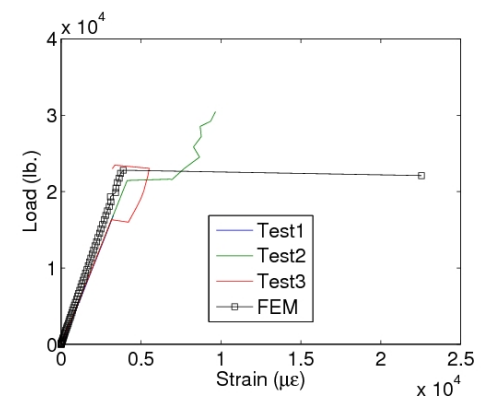

(g) Sg-7

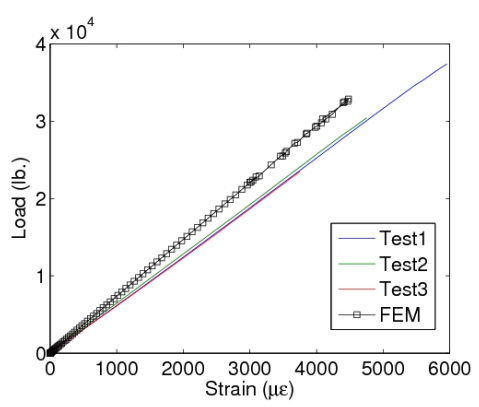

(b) $\mathrm{Sg}-2$

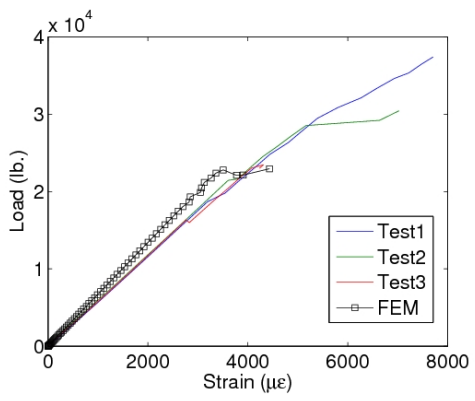

(e) $\mathrm{Sg}-5$

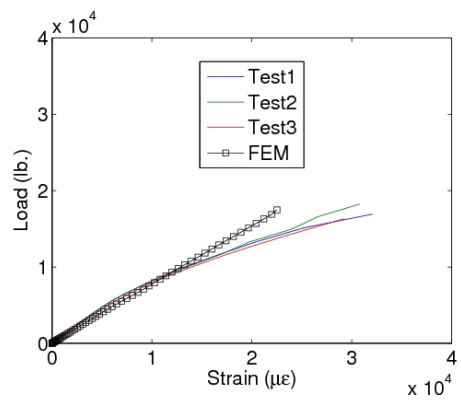

(h) $\mathrm{Sg}-8$

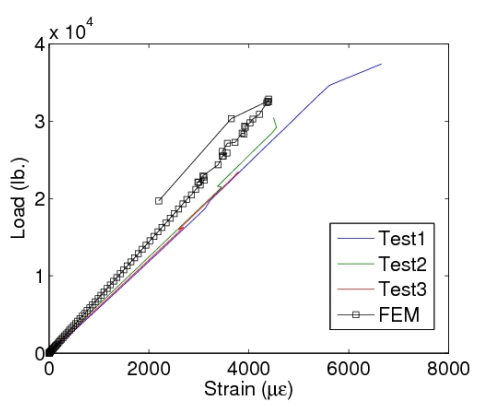

(c) $\mathrm{Sg}-3$

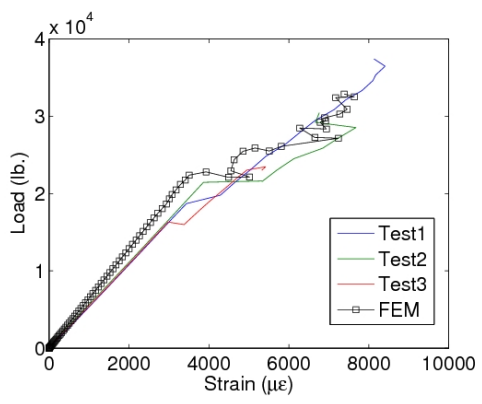

(f) $\mathrm{Sg}-6$

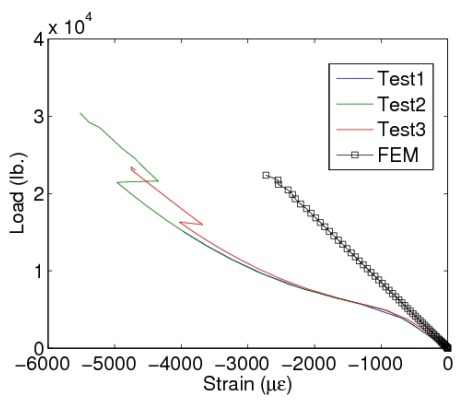

(i) $\mathrm{Sg}-9$

Figure 10. Experimental and numerical load vs. axial strain data for buffer strip panel.

At Sg-1, the initial load at which the strain begins to relax in the numerical simulation is comparable to the load in Test2. This strain relaxation far from the notch is a result of damage occuring near the notch tip. The strain response at $\mathrm{Sg}$-2, which is located on the buffer strip far from the notch, is linear in both the simulation and the experiment. $\mathrm{Sg}-3$, which is located at the boundary of the buffer strip but 6 in. above the notch, exhibits an initial strain relaxation in both Test 2 and the finite element model at the same load level as observed in Sg-1. Jumps in the strain levels at Sg-4 and Sg-6 occur in the model at global loads significantly less than in Test2. This indicates that the damage and failure evolution progresses through the buffer strip more rapidly in the numerical model than in the experiment. However, data for Sg-6, which lies on the buffer strip directly in front of the notch, matches well with the experiment. The same can be seen at Sg-7. Experimental data at the notch tip (Sg-8) displays a high level of non-linearity. This is not observed in the experiment and may be a facet of the extremely steep strain gradients at the notch tip which would require an extremely fine mesh at that region. Similarly, the numerical model does not capture the non-linearity shown in the experiment at Sg-9 in the center of the panel directly above the notch. A relatively large element is present in the model at that location and is used to represent that strain gage; a more refined mesh in that region may capture the 
appropriate response and this is currently being studied.

\section{V.B. Analysis damage and failure mechanisms observed in numerical simulation}

The results of the finite element model indicate that large degrees of microdamage, transverse cracking, and axial failure are confined to regions in front of the notch tip. Thus, $\mathrm{Sg}-1, \mathrm{Sg}-2$, and $\mathrm{Sg}-3$, which lie in regions far from the notch, should not be directly influenced by damage or failure, but rather are affected through redistribution of the strain fields. Figure 11 shows the evolution of the microdamage and transverse crack ISVs with respect to the applied displacement, in each of the top four plies, at the strain gage locations near and in front of the notch tip (Sg-4-Sg-9). The ISVs are normalized by their maximum values $\left(S_{r}^{\max }=230 \mathrm{psi}^{1 / 3}\right.$ and $\left.S_{c r}^{\max }=76 \mathrm{psi}^{1 / 3}\right)$ so that a value of one in Figure 11 corresponds to complete degradation of the appropriate modulus (see Equations (23) and (24)).

$$
\begin{aligned}
& -S_{r}: 45^{\circ} \text { ply } \\
& -S_{r}: 90^{\circ} \text { ply } \\
& -S_{r}:-45^{\circ} \text { ply } \\
& -S_{r}: 0^{\circ} \text { ply } \\
& \triangle-S_{c r}: 45^{\circ} \text { ply } \\
& \triangle-S_{c r}: 90^{\circ} \text { ply } \\
& \triangle S_{c r}:-45^{\circ} \text { ply } \\
& \triangle-S_{c r}: 0^{\circ} \text { ply }
\end{aligned}
$$

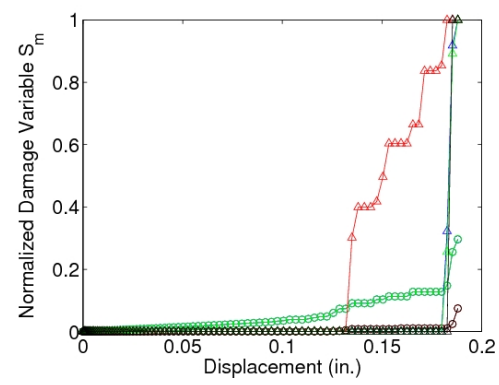

(a) $\mathrm{Sg}-4$

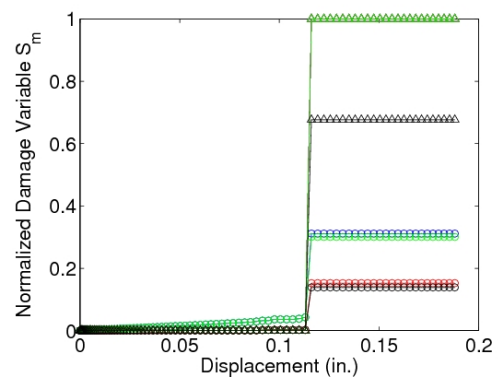

(d) $\mathrm{Sg}-7$

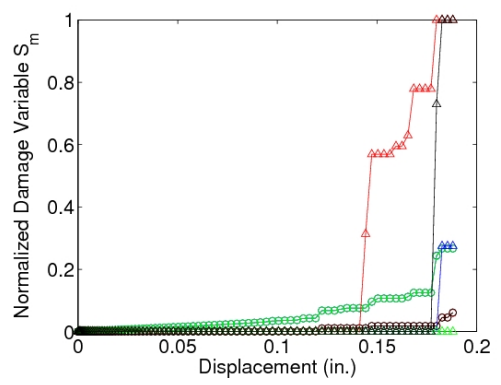

(b) $\mathrm{Sg}-5$

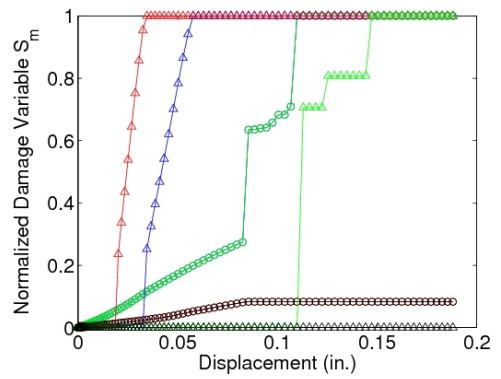

(e) $\mathrm{Sg}-8$

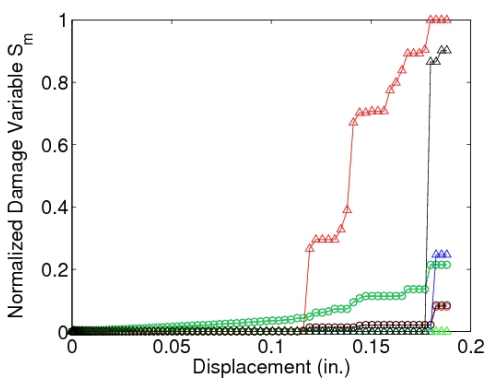

(c) $\mathrm{Sg}-6$

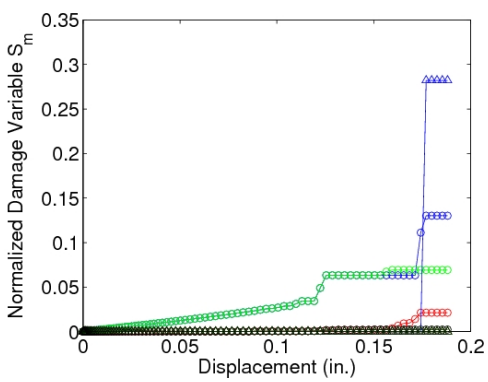

(f) $\mathrm{Sg}-9$

Figure 11. Microdamage and transverse crack evolution at strain gage locations in front notch tip.

Similar damage evolution can be seen at $\mathrm{Sg}-4, \mathrm{Sg}-5$, and $\mathrm{Sg}-6$. Microdamage evolves progressively, and equally, in the $+45^{\circ}$ and $-45^{\circ}$ plies. Very low levels of $S_{r}$ arise at these gages in the $0^{\circ}$ plies, and no microdamage is observed in the $90^{\circ}$ ply until catastrophic failure. Transverse crack evolution remains dormant in all plies, until after a 0.13 in. edge displacement is achieved; after which the degree of damage due to transverse cracking rises rapidly in the $90^{\circ}$ ply until catastrophic failure. This increase in $S_{c r}$ is associated with propagation of axial failure from the notch tip, as is evidenced in the proceeding damage contour analysis. In the $+45^{\circ},-45^{\circ}$, and $0^{\circ}$ plies, $S_{c r}$ remains zero until catastrophic failure.

At the strain gage on the boundary of the buffer strip closest to the notch, only very low levels of microdamage are observed in the $+45^{\circ}$ and $-45^{\circ}$ plies. However, both $S_{r}$ and $S_{c r}$ jump suddenly at an edge displacement of 0.0113 . 
This jump in the ISVs is associated with axial failure evolving from the notch meeting the buffer strip boundary. At the notch tip (Sg-8), transverse cracking in the $+45^{\circ}$ and $90^{\circ}$ layers develop rapidly at low displacement levels. Expeditious advancement in $S_{c r}$ is accompanied by a steady increase of $S_{r}$ in the $+45^{\circ}$ and $-45^{\circ}$ layers near at the notch tip. Less sever microdamage evolution also occurs in the $90^{\circ}$ and $0^{\circ}$ laminae. At a global displacement of 0.1 in. there is a large jump in $S_{c r}$ in the $-45^{\circ}$ layer. $S_{c r}$ remains zero in the $0^{\circ}$ plies; this is most likely a result of axial failure of these layers at the notch tip before transverse cracks can develop. Above the notch at Sg-9, low levels of microdamage in the $+45^{\circ}$ and $-45^{\circ}$ are observed. Overall, the evolution of microdamage in the plies is progressive; whereas, the advancement of transverse cracks is sudden and discontinuous.

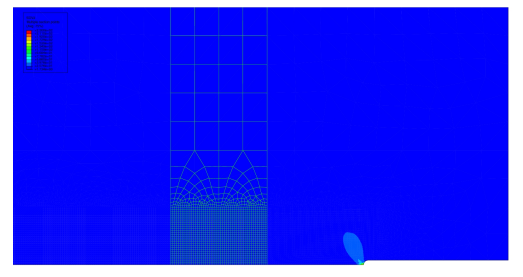

(a) $S_{r}, t=0.0046 \mathrm{~s}$

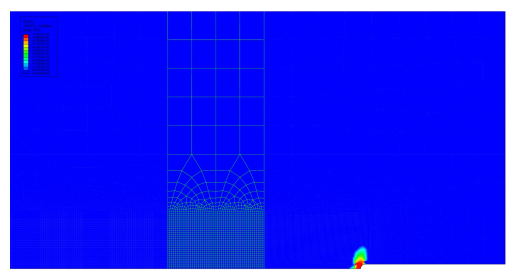

(d) $S_{c r}, t=0.0046 \mathrm{~s}$

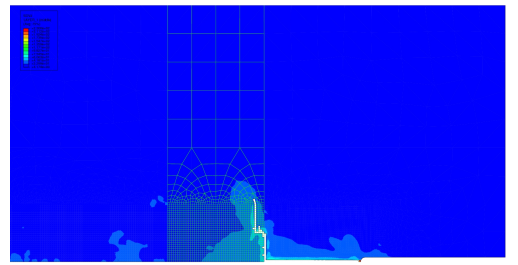

(g) $S_{r}, t=0.0054667 \mathrm{~s}$

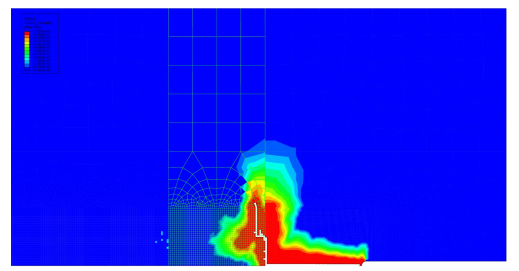

(j) $S_{c r}, t=0.0054667 \mathrm{~s}$

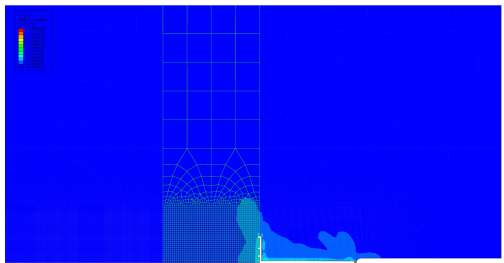

(b) $S_{r}, t=0.0049334 \mathrm{~s}$

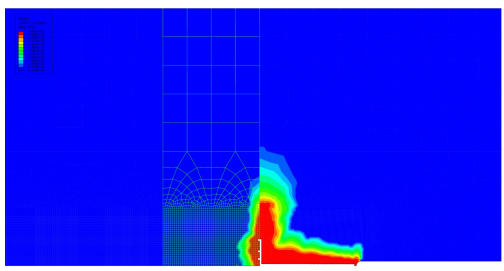

(e) $S_{c r}, t=0.0049334 \mathrm{~s}$

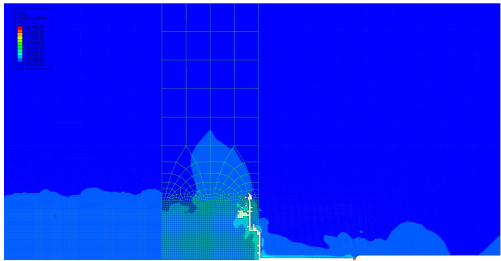

(h) $S_{r}, t=0.0061334 \mathrm{~s}$

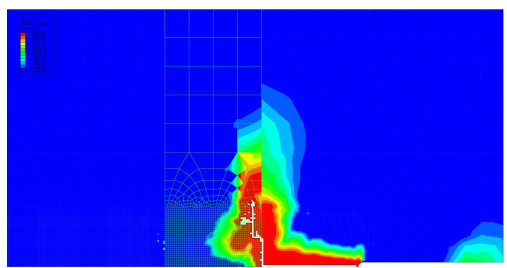

(k) $S_{c r}, t=0.0061334 \mathrm{~s}$

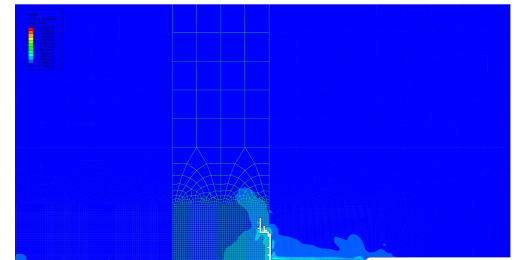

(c) $S_{r}, t=0.005334 \mathrm{~s}$

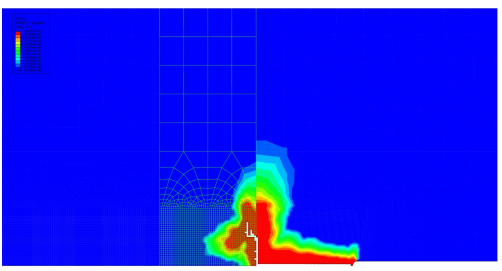

(f) $S_{c r}, t=0.005334 \mathrm{~s}$

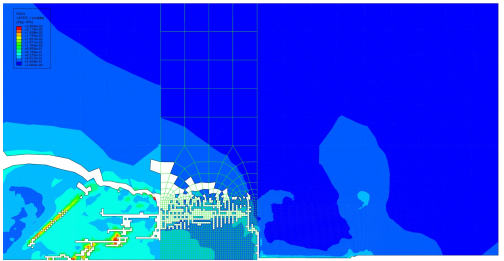

(i) $S_{r}, t=0.0064001 \mathrm{~s}$

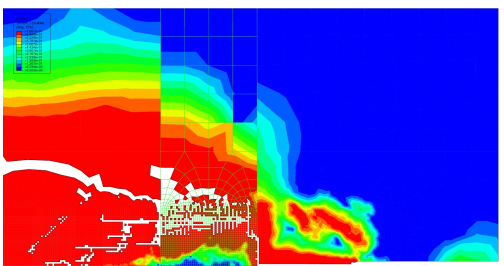

(1) $S_{c r}, t=0.0064001 \mathrm{~s}$

Figure 12. Microdamage, transverse crack evolution and axial failure in top $45^{\circ}$ ply.

Figures 12-15 show matrix microdamage and transverse cracking contours, as well as axial failure paths, at several key time points in the top four layers of the panel acreage and buffer strip. These snapshots clearly depict the evolution of, as well as the interactions between, the three damage mechanisms modeled in this work.

In the outer $45^{\circ}$ layer, prior to initiation of axial failure, a very small amount of microdamage is present near the notch tip and is accompanied by a localized region of maximum transverse cracking damage. Shortly after this, axial 


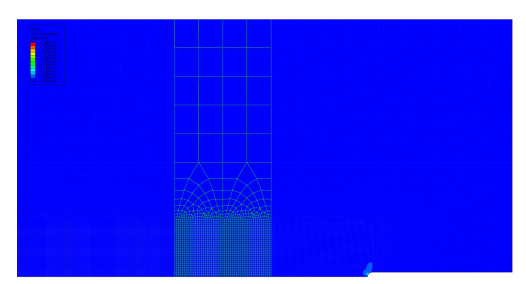

(a) $S_{r}, t=0.0046 \mathrm{~s}$

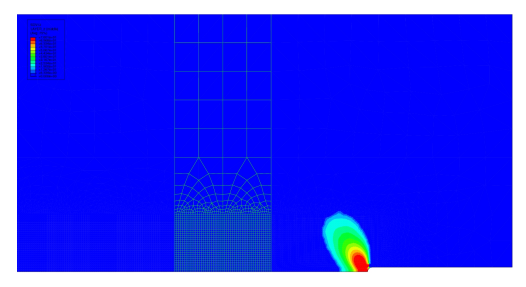

(d) $S_{c r}, t=0.0046 \mathrm{~s}$

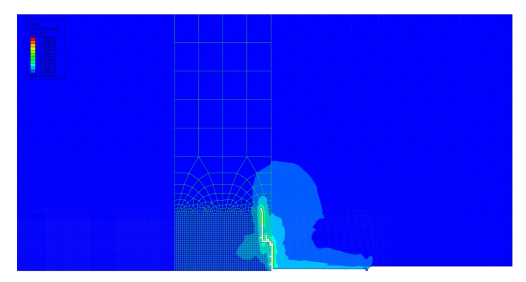

(g) $S_{r}, t=0.0054667 \mathrm{~s}$

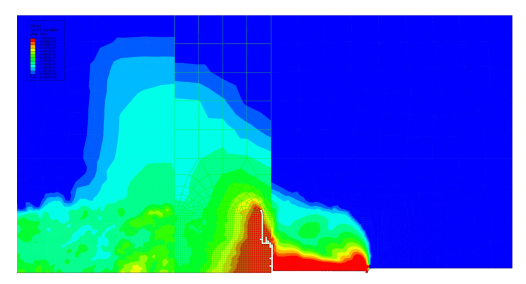

(j) $S_{c r}, t=0.0054667 \mathrm{~s}$

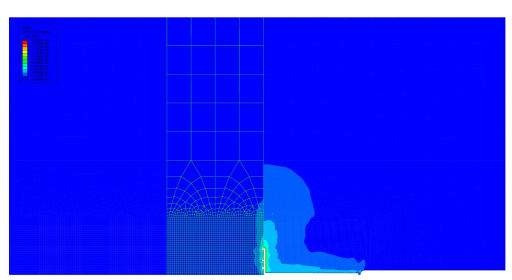

(b) $S_{r}, t=0.0049334 \mathrm{~s}$

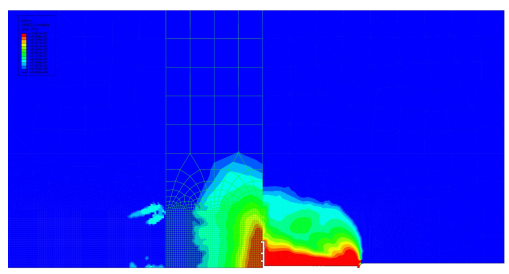

(e) $S_{c r}, t=0.0049334 \mathrm{~s}$

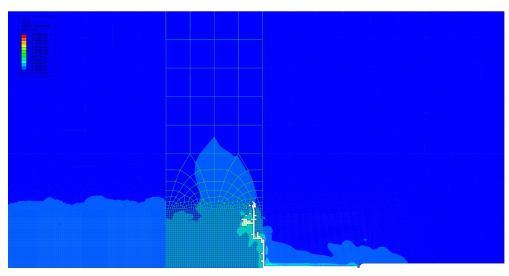

(h) $S_{r}, t=0.0061334 \mathrm{~s}$

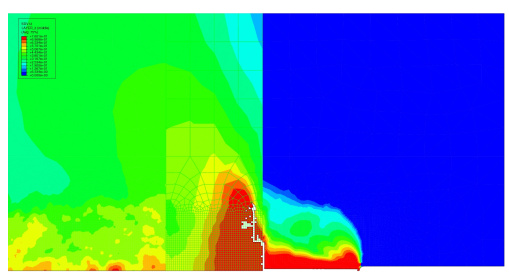

(k) $S_{c r}, t=0.0061334 \mathrm{~s}$

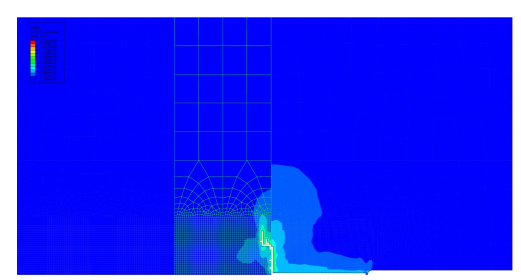

(c) $S_{r}, t=0.005334 \mathrm{~s}$

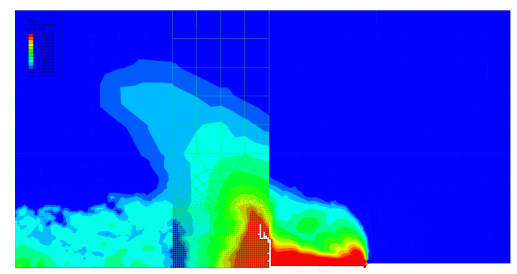

(f) $S_{c r}, t=0.005334 \mathrm{~s}$

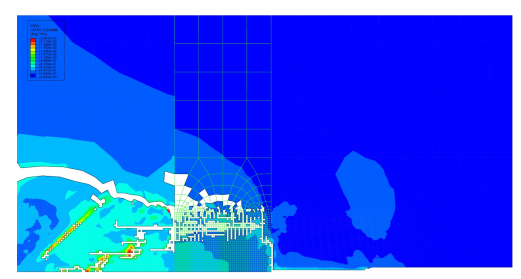

(i) $S_{r}, t=0.0064001 \mathrm{~s}$

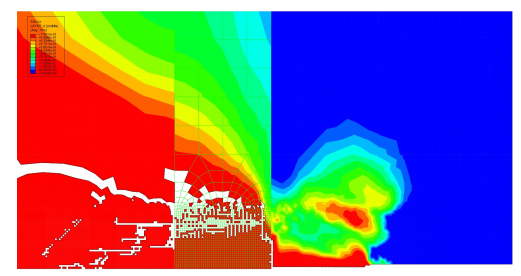

(l) $S_{c r}, t=0.0064001 \mathrm{~s}$

Figure 13. Microdamage, transverse crack evolution and axial failure in top $90^{\circ}$ ply. 


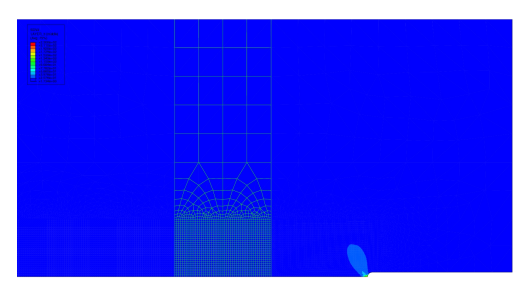

(a) $S_{r}, t=0.0046 \mathrm{~s}$

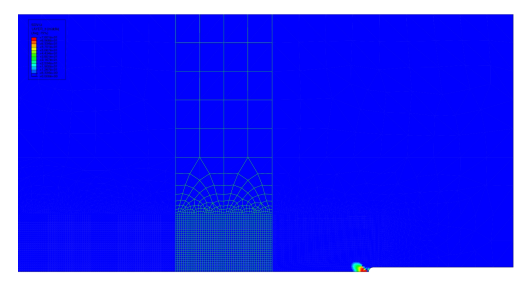

(d) $S_{c r}, t=0.0046 \mathrm{~s}$

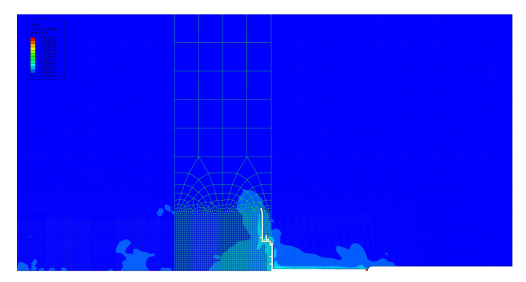

(g) $S_{r}, t=0.0054667 \mathrm{~s}$

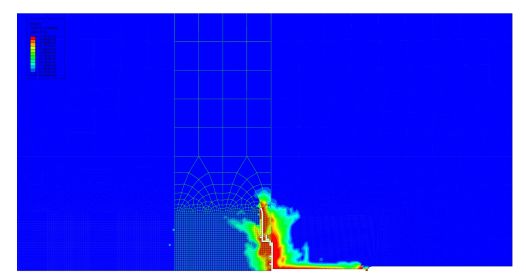

(j) $S_{c r}, t=0.0054667 \mathrm{~s}$

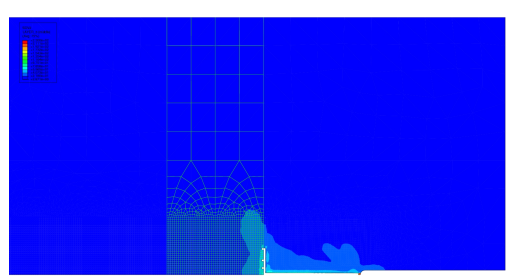

(b) $S_{r}, t=0.0049334 \mathrm{~s}$

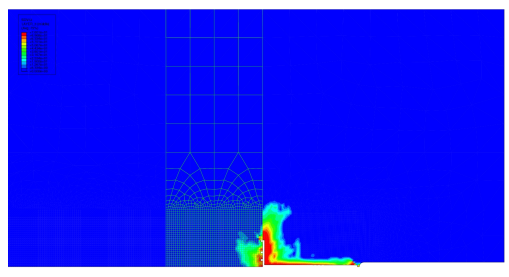

(e) $S_{c r}, t=0.0049334 \mathrm{~s}$

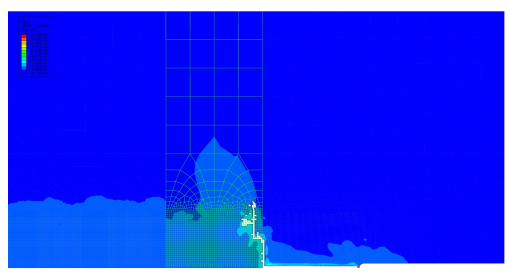

(h) $S_{r}, t=0.0061334 \mathrm{~s}$

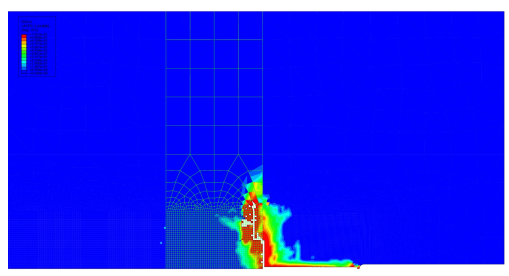

(k) $S_{c r}, t=0.0061334 \mathrm{~s}$

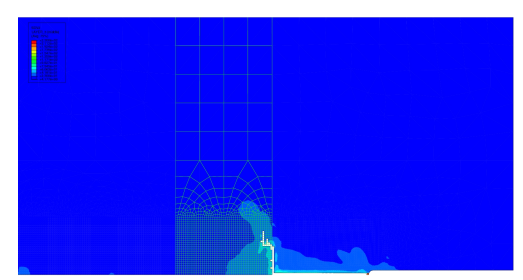

(c) $S_{r}, t=0.005334 \mathrm{~s}$

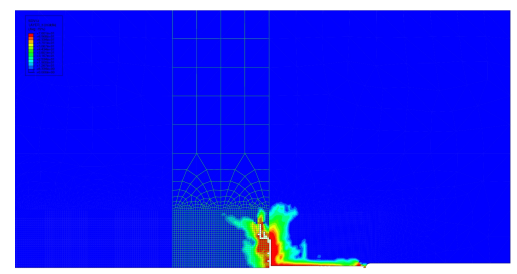

(f) $S_{c r}, t=0.005334 \mathrm{~s}$

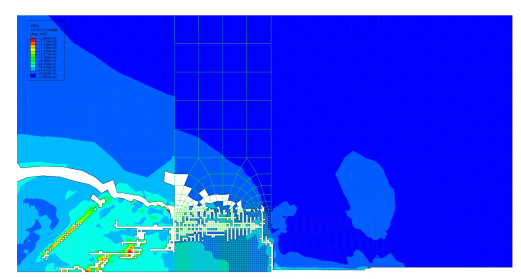

(i) $S_{r}, t=0.0064001 \mathrm{~s}$

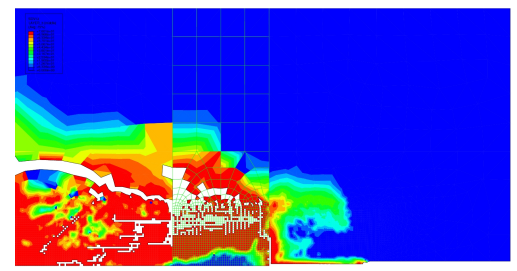

(l) $S_{c r}, t=0.0064001 \mathrm{~s}$

Figure 14. Microdamage, transverse crack evolution and axial failure in top $-45^{\circ} \mathrm{ply}$. 


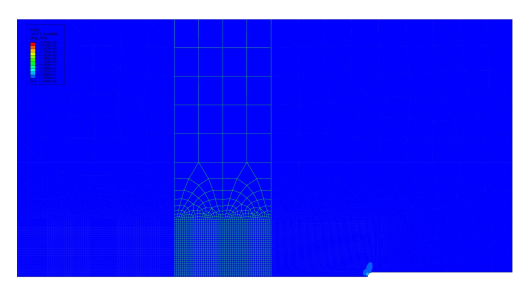

(a) $S_{r}, t=0.0046 \mathrm{~s}$

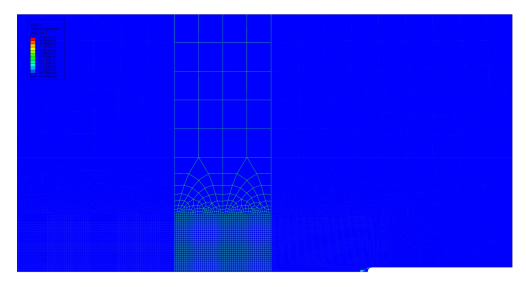

(d) $S_{c r}, t=0.0046 \mathrm{~s}$

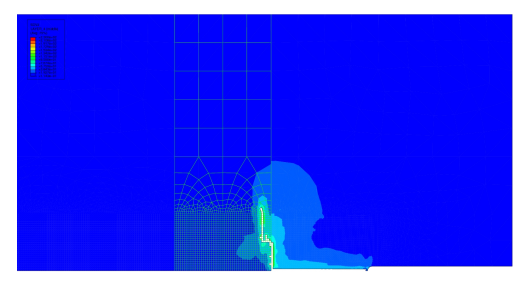

(g) $S_{r}, t=0.0054667 \mathrm{~s}$

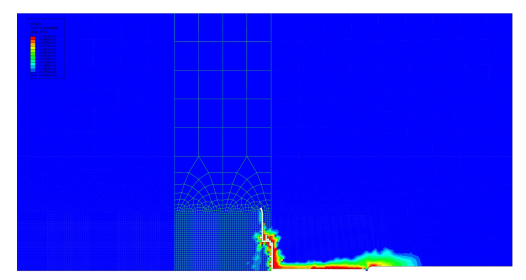

(j) $S_{c r}, t=0.0054667 \mathrm{~s}$

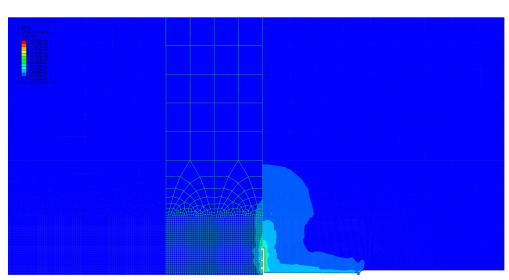

(b) $S_{r}, t=0.0049334 \mathrm{~s}$

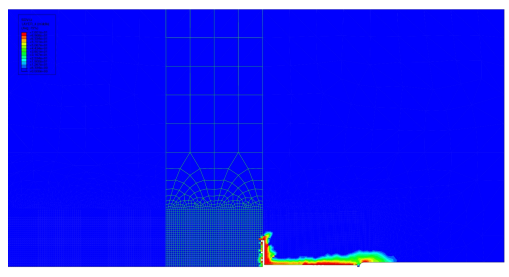

(e) $S_{c r}, t=0.0049334 \mathrm{~s}$

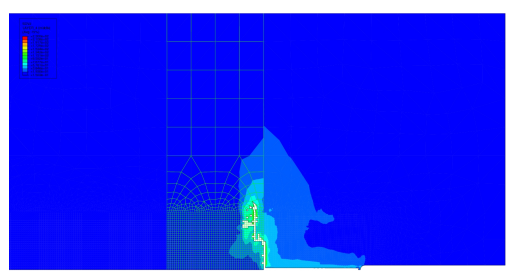

(h) $S_{r}, t=0.0061334 \mathrm{~s}$

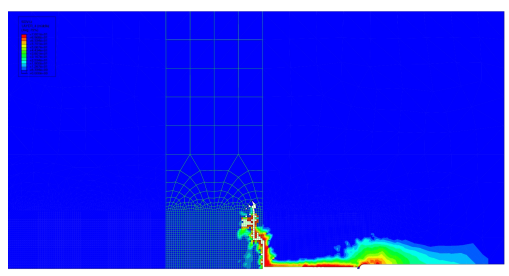

(k) $S_{c r}, t=0.0061334 \mathrm{~s}$

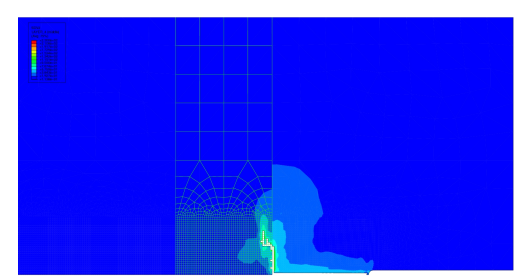

(c) $S_{r}, t=0.005334 \mathrm{~s}$

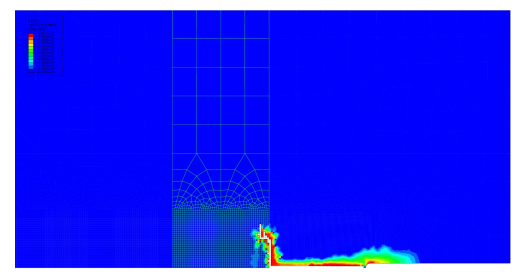

(f) $S_{c r}, t=0.005334 \mathrm{~s}$

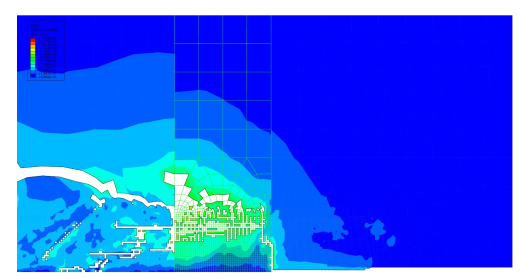

(i) $S_{r}, t=0.0064001 \mathrm{~s}$

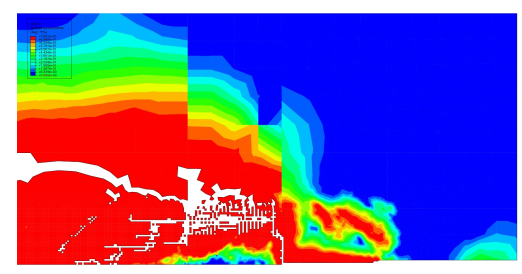

(l) $S_{c r}, t=0.0064001 \mathrm{~s}$

Figure 15. Microdamage, transverse crack evolution and axial failure in $0^{\circ}$ plies. 
failure occurs in these elements. When the maximum strain criterion is satisfied in an element, that element is deleted, and the corresponding void that develops essentially represents a macroscopic crack in the material. Additionally, any elements that have reached $S_{c r}^{\max }$, and have a transverse strain that has surpassed the axial strain allowable, are also removed to prevent excessive element distortion in the simulation. This is a reasonable assumption since transverse failure strains are typically lower than axial failure strains, and an element that has reached $S_{c r}^{\max }$ has most likely been loaded predominantly in the transverse direction and is not contributing axially. When the crack reaches the buffer strips it changes direction and runs parallel to the buffer strip. The crack is then arrested for a brief moment before it advances laterally into the buffer strip (Figure 12(c)). Once inside the buffer strip, the crack turns again and runs along the buffer strip. The subsequent point of arrest for the crack is in a transition region between a very dense mesh and a coarser mesh. It may be that this transition region is influencing the behavior of the crack in a non-physical way; however, similar behavior was observed in regions with a uniformly dense mesh (see Figures ?? and ??). A crack branches from the original crack and propagates perpendicular to the length of the buffer strip. Shortly after this branched crack forms, numerous other branched cracks advance through the buffer strip leading to catastrophic failure of the panel. The evolution of the crack in the $45^{\circ}$ layer is not accompanied by much microdamage. However, large regions exhibiting high levels of transverse cracking surround the macroscopic crack is evident.

The same macroscopic crack progression is observed in the top $90^{\circ},-45^{\circ}$, and $0^{\circ}$ layers. Additionally, the accumulation in all four plies is very similar. The $0^{\circ}$ and $90^{\circ}$ plies exhibit more microdamage encompassing a larger area surrounding the crack as it advances. The $90^{\circ}$ layer exhibits widespread damage due to transverse cracking (Figure 13. In the $0^{\circ}$ layer, high values of $S_{c r}$ are limited to the vicinity surrounding the axial failure path.

The individual damage mechanisms (i.e. microdamage, transverse cracking, and axial failure) are seen to be interactive. Accumulation of $S_{r}$ and $S_{c r}$ near the notch tip leads to a local transfer of load into the $0^{\circ}$ ply from adjacent layers, which subsequently leads to local axial failure. Similarly, the fields surrounding the advancing crack lead to rapid matrix degradation and further crack advancement. Upon, reaching the buffer strip, the path of least resistance to axial failure lies along the longitudinal direction of the buffer strip. However, substantial regions of severe matrix degradation in the non- $0^{\circ}$ plies in the buffer strip provide an avenue for axial failure to occur within the $0^{\circ}$ layers of the buffer strip through load transfer. Once the reinforcement provided by the buffer strip begins to diminish, catastrophic failure is imminent and this is captured in the present work.

\section{Conclusions}

A finite element based implementation of progressive damage accumulation and failure or in short progressive failure analysis (PFA), that is capable of capturing three predominant damage mechanisms in an FRL, namely, matrix shear microdamage, matrix transverse cracking, and axial failure has been presented. The matrix damage mechanisms are modeled using a dual-ISV formulation of ST, which accounts for the damage development mechanisms via the energy required to create structural changes associated with the damage modes in the material. A maximum strain cut-off is chosen to capture axial failure within layers of a laminate. The capabilities of the model are demonstrated by analyzing a center-notched, buffer-strip reinforced composite panel, for which there is experimental data. Good quantitative agreement with global load-displacement, and local strain gage data is exhibited. Moreover, the resulting damage evolution in the model provides insight into the interactions between the individual damage mechanisms within the composite that lead to the global observed failure modes. To obtain subtle details, transparency, and accessibility into the evolution of damage modes in a complex composite structure with experimentation alone would be difficult.

While a significant number of important damage accumulation and failure mechanisms have been captured, delamination failure has not been included in the model, but it can be incorporated by including DCZM elements at the interfaces between adjacent shell or three-dimensional sublaminate layers. Further investigations will focus on the influence of interlamina damage on the response of the buffer strip panel. Additionally, the axial failure theory used does not properly capture the physics involved in axial damage of FRLs. A sensitivity analysis will be performed to determine the influence of the axial failure strain on the ultimate load of, and failure path within, the panel. Future efforts will also attempt to forgo the maximum strain criterion for axial failure in favor of a physically-based, non-local axial damage theory ${ }^{66}$ or a micromechanics based full simulation of axial failure that includes pull-out and frictional slip, ${ }^{65}$ 


\section{References}

${ }^{1}$ Beaumont, P. W. R., Dimant, R. A., and Shercliff, H. R., "Failure processes in composite materials: getting physical," J. Mater. Sci., Vol. 41, 2006, pp. 6526-6546.

${ }^{2}$ Sicking, D. L., Mechanical Characterization of Nonlinear Laminated Composites with Transverse Crack Growth, Ph.D. thesis, Texas A\&M University, College Station, TX, 1992.

${ }^{3} \mathrm{Ng}$, W. H., Salvi, A. G., and Waas, A. M., "Characterization of the in-situ non-linear shear response of laminated fiber-reinforced composites," Compos. Sci. Technol., Accepted February 24, 2010.

${ }^{4}$ Dvorak, G. J. and Laws, N., "Analysis of progressive matrix cracking in composite laminates I. Thermoelastic properties of a ply with cracks," J. Compos. Mater., Vol. 19, 1985, pp. 216-234.

${ }^{5}$ Talreja, R., "Transverse cracking and stiffness reduction in composite laminates," J. Composite Materials, Vol. 19, 1985, pp. $355-275$.

${ }^{6}$ Allen, D. H., Harris, C. E., and Groves, S. E., "A thermomechanical constitutive theory for elastic composites with distributed damage - II. Aplication to matrix cracking in laminated composites," Int. J. Solids Struct., Vol. 23, No. 9, 1987, pp. 1319-1338.

${ }^{7}$ Tan, S. C. and Nuismer, R. J., "A theory for progressive matrix cracking in composite laminates," J. Compos. Mater., Vol. 23, 1989, pp. 1029-1047.

${ }^{8}$ Noda, J., Okabe, T., Takeda, N., and Shimizu, M., "Tensile strength of CFRP cross-ply laminates containing transverse cracks," Adv. Comps. Mater., Vol. 15, No. 1, 2006, pp. 81-93.

${ }^{9}$ Varna, J., Joffe, R., and Talreja, R., "A synergistic damage-mechanics analysis of transverse cracking in $\left[ \pm \theta / 90_{4}\right]_{S}$," Compos. Sci. Technol., Vol. 61, 2001, pp. 657-665.

${ }^{10}$ Yang, Q. and Cox, B., "Cohesive models for damage evolution in laminated composites," Int. J. Frac., Vol. 133, 2005, pp. 107-137.

${ }^{11}$ McCartney, L. N., "Mechanics for the growth of bridged cracks in composite materials: Part I. Basic Principles," J. Compos. Technol. \& Res., Vol. 14, No. 3, 1992, pp. 133-154.

${ }^{12}$ Rudraraju, S. S., Salvi, A., Graikipati, K., and Waas, A. M., "In-plnae fracture of laminated fiber reinforced composites with varying fracture resistance: experimental obesrvations and numerical crack propagation simulations," 50th AIAA/ASME/ASCE/AHS/ASC Structures, Structural Dynamics, and Materials Conference, 4-7 May 2009.

${ }^{13}$ Budiansky, B. and Fleck, N. A., "Compressive failure of fiber composites," J. Mech. Phys. Solids, Vol. 41, No. 1, 1993, pp. $183-211$.

${ }^{14}$ Fleck, N. A., Deng, L., and Budiansky, B., "Prediction of kink width in compressed fiber composites," J. App. Mech., Vol. 62, 1995, pp. 329-337.

${ }^{15}$ Schapery, R. A., "Prediction of compressive strength and kink bands in composites using a work potential," Int. J. Solids Structures, Vol. 32, No. 6, 1995, pp. 739-765.

${ }^{16}$ Yerramalli, C. S. and Waas, A. M., "A failure criterion for fiber reinforced polymer composites under combined compression-torsion loading," Int. J. Solids Structures, Vol. 40, No. 5, 2003, pp. 1139-1164.

${ }^{17}$ Basu, S., Waas, A. M., and Ambur, D. R., "Compressive failure of fiber composites under multiaxial loading," Int. J. Solids Structures, Vol. 44, No. 9, 2006, pp. 2648-2676.

${ }^{18}$ Green, B. G., Wisnom, M. R., and Hallett, S. R., "An experimental investigation into the tensile strength scaling of notched composites," Compos.: Part A, Vol. 38, 2007, pp. 867-878.

${ }^{19}$ Pierron, F., Green, B., and Winsom, M. R., "Full-field assessment of the damage process of laminated composite open-hole tensile specimens. Part I: Methodology," Composites: Part A, Vol. 38, 2007, pp. 2307-2320.

${ }^{20}$ Pierron, F., Green, B., and Winsom, M. R., "Full-field assessment of the damage process of laminated composite open-hole tensile specimens. Part II: Experimental results," Composites: Part A, Vol. 38, 2007, pp. 2321-2332.

${ }^{21}$ Waas, A. M., C. D. Babcock, J., and Knauss, W. G., "An Experimental Study of Compression Failure of Fibrous Laminates in the Presence of Stress Gradients," Int. J. Solids Struct., Vol. 26, No. 9, 1990.

${ }^{22}$ Khamesh, A. and Waas, A. M., "Failure of uniply model composites under compression," ASME Trans. J. of Eng. Mater. Technol., Vol. 114, 1992, pp. 304-310.

${ }^{23}$ Waas, A. M., C. D. Babcock, J., and Knauss, W. G., "An Experimental Study of Compression Failure of Fibrous Laminates in the Presence of Stress Gradients," Int. J. Solids Struct., Vol. 26, No. 9, 1990.

${ }^{24}$ Schapery, R. A., "A theory of mechanical behaviour of elastic media with growing damage and other changes in structure," J. Mech. Phys. Solids, Vol. 38, No. 2, 1990, pp. 1725-1797.

${ }^{25}$ Lemaitre, J. and Chaboche, J.-L., Mechanics of Solid Materials, Cambridge University Press, 1994.

${ }^{26}$ Talreja, R., "Matrix microcracking," Damage characterization by internal variables, edited by R. Talreja, Elsevier Science B.V., 1994.

${ }^{27}$ Ladeveze, P., "Inelastic strains and damage," Damage Mechanics of Composite Materials, edited by R. Talreja, Elsevier Science B.V., 1994.

${ }^{28}$ Lemaitre, J., A Course on Damage Mechanics, 2nd Ed., Springer-Verlag, Berlin, Heidelberg, New York, 1996.

${ }^{29}$ Sukumar, N., Moës, N., Moran, B., and Belytschko, T., "An extended finite element method (X-FEM) for two- and three-dimensional crack modeling," Int. J. Numer. Methods Eng., Vol. 48, No. 11, 2000, pp. 1741-1760.

${ }^{30}$ McCartney, L. N., "Physically based damage models for laminated composites," Proc. Instn Mech. Engrs, Vol. 217, IMechE, 2003, pp. 163-199.

${ }^{31}$ Li, S., Thouless, M. D., Waas, A. M., Schroeder, J. A., and Zavattierid, P. D., "Use of a cohesive zone model to analyze the frcture of a fber-reinfoced polymermatrix composite," Composites Science and Technology, Vol. 65, 2005, pp. 537-549.

${ }^{32}$ Camanho, P. P., Maimi, P., and Davila, C. G., "Prediction of size effects in notched laminates using continuum damage mechanics," Compos. Sci. and Technol., Vol. 67, 2007, pp. 2715-2727.

${ }^{33}$ Schuecker, C. and Pettermann, H. E., "Fiber reinforced laminates: progressive damage modeling based on failure mechanisms," Arch. Comput. Methods Eng., Vol. 15, 2008, pp. 163-184.

${ }^{34}$ Aboudi, J., Mechanics of Composite Materials: A Unified Micromechanical Approach, Elsevier Amsterdam, 1991.

${ }^{35}$ Paley, M. and Aboudi, J., "Micromechanical analysis of composites by the generalized cells model," Mechanics of Materials, Vol. 14, 1992, pp. 127-139.

${ }^{36}$ Bazant, Z. P., "Nonlocal damage theory based on micromechanics of crack interactions," J. Eng. Mech. - ASCE. 
${ }^{37}$ Prat, P. C. and Bazant, Z. P., "Tangential stiffness of elastic materials with systems of growing or closing cracks," J. Mech. Phys. Solids, Vol. 45, No. 4, 1997, pp. 611-636.

${ }^{38}$ Totry, E., Gonzalez, C., and Llorca, J., "Influence of the loading path on the strength of fiber-reinforced composites subjected to transverse compression and shear," Int. J. Solids Structures, Vol. 45, 2008, pp. 1663-1675.

${ }^{39}$ Bednarcyk, B. A., Aboudi, J., and Arnold, S. M., "Micromechanics modeling of composite materials subjected to multiaxial progressive continuum damage," 50th AIAA/ASME/ASCE/AHS/ASC Structures, Structural Dynamics, and Materials Conference, 4-7 May 2009.

${ }^{40}$ Kouznersova, V., Brekelmans, W. A. M., and Baaijens, F. P. T., "An approach to micro-maro modeling of heterogenerous materials," Comput. Mech., Vol. 27, 2001, pp. 37-48.

${ }^{41}$ Bednarcyk, B. A. and Arnold, S. M., "A framework for performing multiscale stochastic progressive failure analysis of composite structures," Proceedings of the 2006 ABAQUS User's Conference, 23-25, May 2006.

${ }^{42}$ Talreja, R., "Multi-scale modeling in damage mechanics of composite materials," J. Mater. Sci., Vol. 41, 2006, pp. 6800-6812.

${ }^{43}$ Kwon, Y. W., Allen, D. H., and Talreja, R., editors, Multiscale Modeling and Simulation of Composite Materials and Structures, Springer, 2008.

${ }^{44}$ Talreja, R., "Multi-scale modeling of composite solids with damage," Proceedings of the American Society for Composites Twenty-third Technical Conference, 9-11, Sept. 2008.

${ }^{45}$ Pineda, E. J., Waas, A. M., Bednarcyk, B. A., and Collier, C. S., "A novel, multiscale high fidelity progressive damage and failure modeling approach for laminated fiber reinforced composites," Proceedings of the American Society for Composites Twenty-third Technical Conference, 7-10, Apr. 2008.

${ }^{46}$ Turon, A., Camanho, P. P., Costa, J., and Davila, C. G., "A damage model for the simulation of delamination in advanced composites under variable-mode loading," Mech. Mater., Vol. 38, No. 11, 2006.

${ }^{47}$ Hallett, S. R., Jiang, W.-G., Khan, B., and Winsom, M. R., "Modelling the interaction between matrix cracks and delamination damage in scaled quasi-isotropic specimens," Compos. Sci. and Technol., Vol. 68, 2008, pp. 80-89.

${ }^{48}$ Guiamatsia, I., Anderson, J. K., Davies, G. A. O., and Iannucci, L., "Decohesion finite element with enriched basis functions for delamination," Compos. Sci. Technol., Vol. 69, 2009, pp. 2616-2624.

${ }^{49}$ Song, S. J. and Waas, A. M., "An energy based model for mixed mode failure of laminated composites," AIAA Journal, Vol. 33 , No. 4, 1995.

${ }^{50}$ Xie, D. E., Salvi, A., Sun, C. E., Waas, A. M., and Caliskan, A., "Discrete cohesive zone model to simulate static fracture in 2-D triaxially braided carbon fiber composites," J. Compos. Mater, Vol. 40, No. 22, 2006.

${ }^{51}$ Xie, D. and Waas, A. M., "Discrete cohesive zone model for mixed-mode fracture using finite element analysis," Engineering Fracture Mechanics, Vol. 73, No. 13, 2006, pp. 1783-1796.

${ }^{52}$ Gustafson, P. A. and Waas, A. M., "The influence of adhesive constitutive parameters in cohesive zone finite element models of adhesively bonded joints," Int. J. Solids Struct., 209, pp. 2201-2215.

${ }^{53}$ Ranatunga, V., Bednarcyk, B. A., and Arnold, S. M., "Modeling delamination in composites via continuum interfacial displacement discontinuities," 50th AIAA/ASME/ASCE/AHS/ASC Structures, Structural Dynamics, and Materials Conference, 4-7 May 2009.

${ }^{54}$ Schapery, R. A. and Sicking, D. L., "A theory of mechanical behaviour of elastic media with growing damage and other changes in structure," Mechanical Behaviour of Materials, edited by A. Bakker, Delft University Press, Delft, The Netherlands, 1995, pp. 45-76.

${ }^{55}$ Pineda, E. J., Waas, A. M., Bednarcyk, B. A., Collier, C. S., and Yarrington, P. W., "Progressive damage and faiure modeling in notched laminated fiber reinforced composites," Int. J. Fract., Vol. 158, 2009, pp. 125-143.

${ }^{56}$ Bogert, P. B. and Satyanaranya, A., private communication, 2010.

${ }^{57}$ Rice, J. R., "Inelastic constitutive relations for solids: an internal-variable theory and its application to metal plasticity," J. Mech. Phys. Solids, Vol. 19, 1971, pp. 433-455.

${ }^{58}$ Sanford, R. J., Principles of Fracture Mechanics, Pearson Education, Inc., 2002.

${ }^{59}$ Laws, N. and Dvorak, G. J., "Progressive transverse cracking in composite laminates," J. Compos. Mater., Vol. 22, 1988, pp. $900-916$.

${ }^{60}$ Gudmundson, P. and Ostlund, S., "Numerical verification of a procedure for calculation of elastic constants in microcracking composite laminates," J. Compos. Mater., Vol. 26, 1992, pp. 2480-2492.

${ }^{61}$ McCartney, L. N., "Theory of stress transfer in a $0^{\circ}-90^{\circ}-0^{\circ}$ cross-ply laminate containing a parallel array of transverse cracks," J. Mech. Phys. Solids, Vol. 40, No. 1, 1992, pp. 27-68.

${ }^{62}$ Jones, R. M., Mechanics of Composite Materials, 2nd Ed., Taylor and Francis, Inc., Philadelphia, 1999.

${ }^{63}$ Basu, S., Computational Modeling of Progrssive Failure and Damage in Composite Laminates, Ph.D. thesis, University of Michigan, Ann Arbor, MI, 2005

${ }^{64}$ SIMULIA, Providence, RI, ABAQUS User's Manual, Vol. 1-3, Version 6.8-1, 2008.

${ }^{65}$ Rudraraju, S., Salvi, A., Garikipati, K., and Waas, A. M., "Micromechanics based full numerical simulation of axial failure in fiber composites," in preparation, 2010

${ }^{66}$ Pineda, E. J., Waas, A. M., Bednarcyk, B. A. ., and Arnold, S. M., "Non-local effects in axial failure of fiber composites," in preparation, 2010 